BONPLANDIA 20(2). 2011

ISSN: 0524-0476

\title{
HUERTOS FAMILIARES PERIURBANOS DE LAS COSTAS DE ENSENADA- BERISSO Y DE LA ISLA MARTÍN GARCÍA (BUENOS AIRES, ARGENTINA)
}

\author{
JULIO A. HURRELL ${ }^{1,3}$, FERNANDO BUET COSTANTINO ${ }^{1}$, JEREMÍAS P. PUENTES ${ }^{1}$, EMILIO A. ULIBARRI ${ }^{2,3}$ \& \\ MARÍA LELIA POCHETTINO ${ }^{1,3}$
}

\begin{abstract}
Summary: Hurrell, J. A., F. Buet Costantino, J. P. Puentes, E. A. Ulibarri \& M. L. Pochettino. 2011. Homegardens at the coasts of Ensenada-Berisso and Martín García Island (Buenos Aires, Argentina). Bonplandia 20(2): 213-229.

This paper presents the results of a study of the current situation of sixteen periurban homegardens at the coasts of Ensenada-Berisso and Martín García Island (Buenos Aires, Argentina) in relation to its historical context of ecological, cultural and economic transformations. In this approach, it becomes evident the adaptive character of the local horticultural practices, as well as its supporting traditional knowledge and its contribution to local agrobiodiversity. The homegardens floristic composition was studied, and ethnobotanical qualitative methods were carried out. Eighty cultivated taxa were recorded, as well as diverse products obtained from them. They are used for family consumption and small-scale marketing, as a supplement to the domestic economy.
\end{abstract}

Key words: Homegardens, periurban areas, Urban Ethnobotany, Buenos Aires, Argentina.

Resumen: Hurrell, J. A., F. Buet Costantino, J. P. Puentes, E. A. Ulibarri \& M. L. Pochettino. 2011. Huertos familiares periurbanos de las costas de Ensenada-Berisso y de la Isla Martín García (Buenos Aires, Argentina). Bonplandia 20(2): 213-229.

Este trabajo presenta los resultados de un estudio de la situación actual de 16 huertos familiares periurbanos de las costas de Ensenada-Berisso y de la Isla Martín García (Buenos Aires, Argentina), en relación a su contexto histórico de transformaciones ecológicas, culturales y económicas, donde se evidencia el carácter adaptativo de las prácticas hortícolas, los saberes tradicionales que las sustentan y su aporte a la agrobiodiversidad local. Se relevó la composición florística de los huertos, y se aplicaron métodos cualitativos para el relevamiento de datos etnobotánicos. Se registraron 80 taxones cultivados y productos obtenidos a partir de estos, para consumo familiar y comercialización a pequeña escala, como suplemento para la economía doméstica.

Palabras clave: Huertos familiares, áreas periurbanas, Etnobotánica urbana, Buenos Aires, Argentina.

\footnotetext{
${ }^{1}$ Laboratorio de Etnobotánica y Botánica Aplicada (LEBA), Facultad de Ciencias Naturales y Museo, Universidad Nacional de La Plata, Calle 64 nro. 3, 1900-La Plata, Buenos Aires, Argentina.

${ }^{2}$ Instituto de Botánica Darwinion (ANCEFN-CONICET), Labardén 200, 1642-San Isidro, Buenos Aires, Argentina.

${ }^{3}$ Investigador CONICET.

E-mail: juliohurrell@gmail.com
} 


\section{Introducción}

Este trabajo incluye resultados obtenidos a partir de una línea de investigación sobre huertos familiares de los sectores periurbanos de la región rioplatense, desarrollada en el Laboratorio de Etnobotánica y Botánica Aplicada (LEBA), Facultad de Ciencias Naturales y Museo, Universidad Nacional de La Plata. La región rioplatense abarca el área de influencia del río de La Plata, desde el Delta del Paraná inferior, las islas sedimentarias de su frente de avance, la isla Martín García y la ribera bonaerense, hasta Punta Indio (Hurrell, 2008). La región incluye distintas fisonomías vegetales (selva marginal, bosques y matorrales hidrófilos, pajonales, juncales) $\mathrm{y}$, asimismo, la mayor conurbación de la Argentina, que abarca las aglomeraciones urbanas contiguas del Gran Buenos Aires: la Capital Federal y 24 partidos aledaños de la Provincia de Buenos Aires; y del Gran La Plata, conformado por los partidos bonaerenses de Ensenada, Berisso y La Plata (Gemini, 2003; Barsky \& Fernández, 2004; AABA, 2010).

De este modo, la región contiene sectores netamente urbanos, otros no urbanizados con vegetación espontánea (incluidas algunas áreas protegidas), y sectores periurbanos, de transición entre los sectores urbanos y rurales, con límites móviles según los ritmos de la urbanización (Barsky, 2005, 2010). En el sector periurbano se encuentra el área hortícola bonaerense, que abastece de hortalizas, verduras y frutas frescas a los habitantes del sector urbano propiamente dicho, y de otras provincias argentinas (Benencia, 1997; Feito, 2007; Benencia \& al., 2009). La actividad hortícola incluye, además, los 1lamados huertos familiares, es decir, terrenos de poca extensión, próximos a las viviendas, donde se cultivan hortalizas y, asimismo, frutales y plantas aromáticas, para el consumo familiar o para su venta ocasional, a escala restringida, como suplemento para la economía doméstica (Buet \& al., 2010; Pochettino, 2010).

El estudio de los huertos familiares es un tema de interés creciente en Etnobotánica, que aporta a la conservación de la diversidad agrobiológica (en especial, la infraespecífica) y cultural: las estrategias de manejo no se orientan según las reglas del mercado, sino por preferencias, usos culinarios y tradiciones familiares. Así, estos huertos constituyen respuestas adaptativas a partir de la experiencia del grupo humano en su ambiente. Esta temática ha motivado diversas contribuciones en distintas partes del mundo (Nazarea, 1998; Lamont \& al., 1999; Gaytán \& al., 2001; Vogl \& al., 2002; Vogl-Lukasser \& al., 2002; Wagner, 2002; Watson \& Eyzaguirre, 2002; Blanckaert \& al., 2004; Vogl-Lukasser \& Vogl, 2004; Albuquerque \& al., 2005; Das \& Das, 2005; Huai \& Hamilton, 2009); y también en nuestro país, muchas de ellas desarrolladas por el equipo de trabajo del LEBA (Martínez \& al., 2003; Maidana \& al., 2005; Pochettino \& al., 2006; Turco \& al., 2006; Del Río \& al., 2007; Pérez \& al., 2008; Buet \& al., 2010; Pochettino, 2010).

El objetivo de este trabajo es presentar los resultados de los relevamientos realizados en huertos familiares emplazados en cuatro sitios del área de estudio: la Isla Martín García, en el tramo superior del río de la Plata; la Isla Santiago, en la ribera del Partido de Ensenada; la Isla Paulino y Los Talas, en la costa del Partido de Berisso. Se evalúa el estado actual de los huertos según su contexto histórico, su composición florística, usos y destino de la producción. Martín García difiere en distintos aspectos bioculturales de los otros sitios; estos, en tanto, tienen rasgos históricos y ecológicos semejantes, por lo cual es posible establecer comparaciones entre huertos de diferentes contextos.

\section{Área de estudio}

El área de estudio comprende distintos huertos familiares del sector sur de la región rioplatense, en los partidos de Ensenada (Isla Santiago) y Berisso (Isla Paulino, Los Talas), ligados por tradiciones comunes de larga data, y los huertos familiares de la Isla Martín García, en el norte de la región, que son emprendimientos más recientes (Fig. 1).

Los actuales partidos de Ensenada, Berisso y La Plata se originaron a fines del siglo XIX, como resultado del emplazamiento de la nueva capital provincial, la ciudad de La Plata, y 
la construcción de su puerto. El origen de Ensenada es portuario (se remonta a 1801, con la fundación del pueblo de Ensenada); el de Berisso, en cambio, es industrial (asentamiento de saladeros, en la década de 1870). Ambos partidos quedaron separados por el canal de acceso al puerto de La Plata, cuyo dragado data de 1883. Este dividió la antigua Isla Santiago en dos: Santiago Oeste (la actual Isla Santiago, Ensenada), y Santiago Este (la actual Isla Paulino, Berisso). A fin de siglo, además, una intensa corriente inmigratoria europea se asentó en la zona, en especial italianos, españoles, portugueses y polacos, aunque se cuentan más de 20 colectividades (la ciudad de Berisso fue declarada "capital provincial del inmigrante"). Los inmigrantes trabajaron en la construcción de La Plata, su puerto y canal de acceso, y se afincaron en zonas costeras, muchas de ellas fueron tierras fiscales otorgadas a cambio de desplegar actividades fruti-hortícolas, en las que volcaron las tradiciones de sus respectivos orígenes (Sanucci, 1972; Michellod, 2000; García, 2010). Así, comenzó la producción del "vino de la costa", gracias a la implantación de Vitis labrusca L., "vid americana", mediante el sistema de parral, adaptado a las condiciones locales (Marasas \& Velarde, 2000).

En la primera mitad del siglo xx, el desarrollo industrial de toda la región (frigoríficos, establecimientos textiles, la petroquímica, el astillero de Ensenada), y las frecuentes crecidas del río, determinaron que muchos habitantes dedicados a las prácticas hortícolas y frutícolas se radicaran en las áreas urbanizadas vecinas (que se expandieron junto con la industrialización), porque ofrecían nuevas posibilidades de trabajo (García, 2010). El despoblamiento fue muy marcado en ciertos sectores, como la Isla Paulino: en su época de esplendor vivían en ella más de 70 familias vinculadas con la horticultura, la pesca y el turismo; en la actualidad, sólo 7 familias residen en la isla de forma permanente, y otras 5 conservan sus viviendas como casas de fin de semana (Buet \& al., 2010). Según la Prefectura Naval Argentina, hay 32 residentes y 13 viviendas en total.

Laexpansióninicial de los terrenos cultivados produjo la retracción de la vegetación original; en especial, la de bosques y matorrales

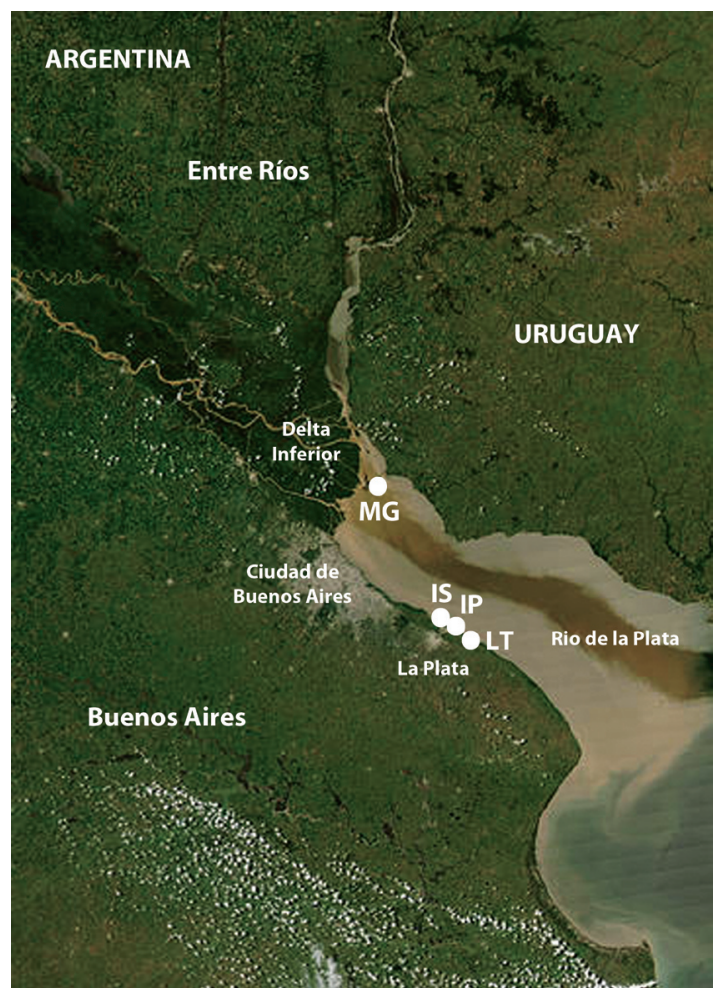

Fig. 1. Imagen satelital de la NASA, enero de 2003, del sector austral de la Cuenca del Plata, con los tramos inferiores de los ríos Paraná y Uruguay, el delta inferior y el río de la Plata. Se indica la localización de la Isla Martín García (MG), Isla Santiago (IS), Isla Paulino (IP) y Los Talas (LT), donde se encuentran los huertos familiares relevados.

higrófilos (Cabrera, 1949). Tras el abandono, especies nativas del área colonizaron las zonas cultivadas y abandonadas, y en éstas, asimismo, especies exóticas perduraron o ingresaron, y se naturalizaron; por ejemplo, Carya illinoinensis (Wangenh.) K. Koch (Hurrell \& al. 2011a). Los cambios en las fisonomías vegetales, con pulsos de retracción y expansión, en correlato con los ritmos del uso del espacio (cultivos, urbanización), son comunes en toda la región rioplatense (Hurrell, 2008). Las prácticas vitivinícolas, en particular, tuvieron un importante deterioro a partir de la segunda mitad del siglo Xx, que contrastó con su gran desarrollo anterior. Sin embargo, ha habido una reactivación, en los últimos años, gracias a la formación de cooperativas en el partido de Berisso (Marasas \& Velarde, 2000; Link 
\& Schiavo, 2003; Velarde \& al., 2008), que recuperan la actividad y, al mismo tiempo, rescatan las tradiciones que constituyeron las bases de su propio origen.

La Isla Paulino, con unas 1300 ha, a pesar de ubicarse a $10 \mathrm{~km}$ de la ciudad de La Plata se encuentra hoy en una situación precaria: no hay servicios de luz, agua potable y gas, y cuenta con un teléfono público; no hay escuela, y un único puesto sanitario presta un servicio de enfermería durante el verano; el transporte fluvial presenta horarios restringidos $\mathrm{y}$, a veces, se ve interrumpido (Buet \& al., 2010; Hernández \& al., 2010). Los Talas, en cambio, cuenta con servicios de luz, de agua potable, teléfono y gas, y sus habitantes, 494 en 2001 (INDEC, 2011), acceden por diversos caminos a las escuelas y centros de salud de las ciudades de Berisso, Ensenada y La Plata (Hernández \& al., 2009). En esta localidad, el área de estudio corresponde a unas 300 ha, ya que sólo se consideró el sector costero, donde se encuentran huertos y viñedos.

La Isla Santiago, con sus 800 ha, se halla a $15 \mathrm{~km}$ de la ciudad de La Plata. A diferencia de la Isla Paulino se puede ingresar, además de por la vía fluvial, por vía terrestre (llega una de las líneas platenses de colectivos). Tiene una escuela inicial y primaria, y suministro eléctrico, agua potable y teléfono, pero no hay gas natural. En 2001, contaba con 237 habitantes, incluyendo la Escuela y Liceo Naval Río Santiago (INDEC, 2011); según la Prefectura Naval Argentina, en la isla viven 193 personas y hay 83 viviendas en total. Su situación actual es de recuperación, tras décadas de deterioro de la actividad hortícola, subocupación laboral, y el consecuente abandono.

La Isla Martín García, se sitúa en el extremo norte del río de la Plata, a 3,5 km de la costa uruguaya y a $37,5 \mathrm{~km}$ de la argentina, se encuentra bajo jurisdicción directa de la Dirección de Islas del Ministerio de Gobierno de la Provincia de Buenos Aires. Desde 1973, con la firma del Tratado del Río de la Plata entre Uruguay y la Argentina, es una reserva natural, además de sitio histórico (Llambí, 1973; Alfonsín, 2002). Como punto geopolítico estratégico, estuvo bajo control militar desde el siglo XIX, y fue transferida a la provincia de Buenos Aires en 1985, al retirarse la Armada
Argentina de forma definitiva. En la isla, todos los terrenos son fiscales, sus habitantes trabajan para el gobierno provincial (servicios, mantenimiento), o tienen concesiones para explotaciones comerciales (restaurantes, camping, almacén), a cambio del pago de un canon.

Con unas 200 ha, tiene basamento rocoso (uno de los más antiguos del país), a diferencia del resto de las islas sedimentarias del Plata, pero recibe aportes constantes de sedimentos que modifican la conformación y vegetación de sus costas (Dalla Salda, 1981; González \& Ravizza, 1987; Codignotto, 1990). La Isla Martín García tiene unos 200 habitantes (INDEC, 2011), no hay gas natural, pero sí agua potable y corriente eléctrica (con planta potabilizadora y usina propias), y teléfono; funciona un hospital, escuelas de nivel inicial, primario y secundario, y lanchas de línea que la conectan con la estación fluvial del Tigre. Además de la vía fluvial, se puede acceder por vía aérea, dado que cuenta con un aeródromo (su extensa pista de aterrizaje fue construida en los tiempos de la Armada).

En Martín García, al igual que en las zonas costeras de Ensenada-Berisso, las áreas urbanizadas y de vegetación espontánea han sufrido pulsos de expansión y retracción, unas respecto de las otras. En las costas de la isla, además de pajonales, matorrales y bosques higrófilos, se halla una selva marginal similar a la del delta, con mayor complejidad florística que la selva que alcanza la zona de Punta Lara, en Ensenada (Cabrera \& Dawson, 1944; Burkart, 1957; Hurrell, 2008). A diferencia de Berisso y Ensenada, la horticultura no es una práctica característica de la población de la isla Martín García; su principal actividad económica se basa en el turismo. Sus huertos familiares se circunscriben a pequeños emplazamientos que datan de los últimos 35 años, excepto una plantación de cítricos, implantada por la Armada y abandonada antes de su retiro de la isla.

\section{Materiales y Métodos}

Desde 2006 hasta la fecha se relevaron 16 huertos familiares: 5 en la Isla Martín García, 
5 en la Isla Santiago, 3 en la Isla Paulino y 3 en Los Talas. Se evaluó su composición florística, se exploraron las áreas circundantes y se coleccionaron ejemplares de referencia, que fueron identificados y depositados para su documentación en las colecciones del LEBA y los herbarios LP (Plantas Vasculares, Museo de La Plata) y SI (Instituto de Botánica Darwinion, San Isidro). Para la nomenclatura de los taxones se tomaron como referencia bases de datos de distintas instituciones (IBODA, 2009, Tropicos, 2011). Además, se han coleccionado muestras de partes de plantas y productos elaborados a partir de ellas, los cuales se han depositado en el LEBA.

Para el relevamiento de datos etnobotánicos se siguieron métodos cualitativos usuales (Alexíades \& Sheldon, 1996; Albuquerque \& Lucena, 2004; Martin, 2004), en especial: observación sistemática en los espacios donde se desarrolla la actividad hortícola; listados libres para el inventario de taxones cultivados; entrevistas semiestructuradas y abiertas, orientadas según criterios específicos para huertos familiares (Vogl \& al., 2004). Además, se revisó bibliografía pertinente sobre las plantas observadas y sus usos.

Según las características de las localidades y huertos, se registró información vinculada con prácticas hortícolas en desuso (taxones cuyo cultivo fue abandonado) y con los criterios de selección de las especies actualmente cultivadas (especies de uso amplio o generalizado, y las ligadas a tradiciones familiares). El total de informantes asciende a 25 personas adultas de ambos sexos, involucradas en la actividad hortícola y en la elaboración de productos derivados, su modo de consumo y eventual comercialización.

\section{Resultados y Discusión}

Todos los huertos familiares relevados ocupan un espacio próximo a las viviendas, y su emplazamiento puede constituir un sitio único, o distintos lugares con mayor o menor grado de demarcación. Por lo común, se establece un sector para el cultivo de las plantas aromáticas. Los árboles frutales, por lo general pocos ejemplares, se hallan dispersos o más o menos agrupados. Los sectores de viñedos, de escaso desarrollo actual en la Isla Paulino, se hallan contiguos a los huertos y conforman con estos una misma unidad. En Los Talas, los viñedos ocupan terrenos más amplios y son los huertos familiares los que se hallan adosados a aquellos.

Las especies, subespecies y variedades relevadas en los distintos huertos familiares de las diferentes localidades se presentan en la Tabla 1; se incluyen las familias, nombres científicos y vulgares, partes de las plantas y productos obtenidos a partir de ellas, sus usos, las localidades donde se han hallado, los fines del cultivo (doméstico, comercial), las modalidades de los relevamientos realizados y las muestras obtenidas, bajo los leg. Fernando Buet Costantino \& al. (FB) y Julio A. Hurrell \& al. $(\mathrm{JH})$.

La Tabla 2 indica la presencia/ausencia de los taxones relevados en los distintos huertos familiares que se hallan en las localidades del área de estudio. Los resultados se ajustan a los cinco años de relevamientos, y algunos taxones se cultivan sólo algunos años, mientras otros son continuos. Este es un rasgo común a todos los huertos observados.

El total de taxones asciende a 80 especies, subespecies y variedades, correspondientes a 27 familias. La familia con mayor cantidad de taxones es Rosaceae: 11 (13,75\% del total); le siguen Cucurbitaceae y Lamiaceae, cada una con 8 taxones (10\%), Asteraceae, Leguminosae y Rutaceae, cada una con 5 (6,25\%), y Alliaceae y Solanaceae, 4 taxones cada una (5\%). Estas familias comprenden el $62,5 \%$ de los taxones relevados y, en ellas, se hallan representados los distintos tipos de cultivos que caracterizan estos huertos: a) hortalizas (verduras y legumbres): Alliaceae, Asteraceae (en parte), Cucurbitaceae, Leguminosae, Solanaceae; b) plantas aromáticas y medicinales: Asteraceae (en parte), Lamiaceae, Verbenaceae; y c) frutales: Rosaceae, Rutaceae.

En los huertos familiares de la Isla Santiago se encuentra la mayor riqueza de taxones cultivados: 72; en la Isla Paulino se registraron 48 taxones; en la Isla Martín García, 47; en Los Talas, 41. A uno de los huertos de la Isla Santiago corresponde la mayor riqueza de taxones: $63(78,75 \%$ del total de taxones 
Tabla 1. Especies cultivadas en los huertos familiares relevados, usos y características del cultivo.

\begin{tabular}{|c|c|c|c|c|c|c|}
\hline Familias/Especies & N. vulgares & $\begin{array}{c}\text { Partes y productos } \\
\text { derivados y sus usos }\end{array}$ & $\begin{array}{c}\text { Locali- } \\
\text { dades }\end{array}$ & $\begin{array}{l}\text { Fines del } \\
\text { cultivo }\end{array}$ & $\begin{array}{l}\text { Releva- } \\
\text { mientos }\end{array}$ & Muestras \\
\hline \multicolumn{7}{|l|}{ ACTINIDIACEAE } \\
\hline $\begin{array}{l}\text { Actinidia chinensis } \\
\text { Planch. var. deliciosa (A. } \\
\text { Chev.) A. Chev. }\end{array}$ & Kiwi & $\begin{array}{l}\text { Frutos comestibles } \\
\text { (fruta fresca) y } \\
\text { medicinales: para } \\
\text { prevenir y combatir los } \\
\text { resfríos. }\end{array}$ & IS & $\begin{array}{l}\text { Doméstico } \\
\text { en la } \\
\text { actualidad } \\
\text { (antes, } \\
\text { comercial) }\end{array}$ & $\begin{array}{l}\text { OB, LL, } \\
\text { ES }\end{array}$ & $\begin{array}{l}\text { FB } 467 \\
\text { (LP) } \\
\text { FB } 497 \\
\text { (LEBA) }\end{array}$ \\
\hline \multicolumn{7}{|l|}{ Alliaceae } \\
\hline Allium cepa L. var. cepa & Cebolla & $\begin{array}{l}\text { Bulbos comestibles, } \\
\text { condimenticios y } \\
\text { medicinales: diurético, } \\
\text { pectoral, depurativo, } \\
\text { carminativo. }\end{array}$ & $\begin{array}{l}\text { MG, IS, } \\
\text { IP, LT }\end{array}$ & Doméstico & $\begin{array}{l}\text { OB, LL, } \\
\text { EA, ES }\end{array}$ & $\begin{array}{l}\text { FB } 513 \\
(\text { LEBA) }\end{array}$ \\
\hline Allium ampeloprasum L. & Puerro & $\begin{array}{l}\text { Bulbos comestibles, } \\
\text { condimenticios y } \\
\text { medicinales: diurético, } \\
\text { digestivo, carminativo, } \\
\text { pectoral. }\end{array}$ & $\begin{array}{l}\text { MG, IS, } \\
\text { IP, LT }\end{array}$ & Doméstico & $\begin{array}{l}\mathrm{OB}, \mathrm{LL} \\
\mathrm{EA}, \mathrm{ES}\end{array}$ & $\begin{array}{l}\text { FB } 514 \\
\text { (LEBA) }\end{array}$ \\
\hline Allium fistulosum L. & $\begin{array}{l}\text { Cebolla de } \\
\text { verdeo }\end{array}$ & $\begin{array}{l}\text { Bulbos comestibles, } \\
\text { condimenticios y } \\
\text { medicinales: diurético, } \\
\text { depurativo, vermífugo. }\end{array}$ & $\begin{array}{l}\text { MG, IS, } \\
\text { LT }\end{array}$ & Doméstico & $\begin{array}{l}\text { OB, LL, } \\
\text { EA, ES }\end{array}$ & $\begin{array}{l}\text { FB } 528 \\
\text { (LEBA) }\end{array}$ \\
\hline Allium schoenoprasum L. & $\begin{array}{l}\text { Ciboulette/ } \\
\text { Cebollín }\end{array}$ & $\begin{array}{l}\text { Bulbos comestibles, } \\
\text { condimenticios y } \\
\text { medicinales: diurético, } \\
\text { depurativo. }\end{array}$ & $\begin{array}{l}\text { MG. IS, } \\
\text { LT }\end{array}$ & Doméstico & $\begin{array}{l}\mathrm{OB}, \mathrm{LL} \\
\mathrm{EA}, \mathrm{ES}\end{array}$ & $\begin{array}{l}\text { FB } 376 \\
\text { (LP) }\end{array}$ \\
\hline \multicolumn{7}{|l|}{ ANACARDIACEAE } \\
\hline Mangifera indica $\mathrm{L}$. & Mango & $\begin{array}{l}\text { Frutos comestibles } \\
\text { (fruta fresca). Hojas } \\
\text { medicinales: purgantes. }\end{array}$ & IS & Doméstico & $\mathrm{OB}, \mathrm{EA}$ & $\begin{array}{l}\text { FB } 504 \\
\text { (LEBA) }\end{array}$ \\
\hline \multicolumn{7}{|l|}{ APIACEAE } \\
\hline Apium graveolens $\mathrm{L}$. & Apio & $\begin{array}{l}\text { Tallos y hojas } \\
\text { comestibles y } \\
\text { medicinales: digestivo, } \\
\text { carminativo, diurético. }\end{array}$ & $\begin{array}{l}\text { MG, IS, } \\
\text { IP, LT }\end{array}$ & Doméstico & $\begin{array}{l}\mathrm{OB}, \mathrm{LL} \\
\mathrm{EA}, \mathrm{ES}\end{array}$ & $\begin{array}{l}\text { FB } 550 \\
\text { (LEBA) }\end{array}$ \\
\hline $\begin{array}{l}\text { Daucus carota } \text { L. subsp. } \\
\text { sativus (Hoffm.) Schübl. } \\
\& \text { G. Martens }\end{array}$ & Zanahoria & Raíces comestibles. & $\begin{array}{l}\text { MG, IS, } \\
\text { IP, LT }\end{array}$ & Doméstico & $\begin{array}{l}\mathrm{OB}, \mathrm{LL} \\
\mathrm{EA}, \mathrm{ES}\end{array}$ & $\begin{array}{l}\text { FB } 378 \\
\text { (LP) }\end{array}$ \\
\hline $\begin{array}{l}\text { Petroselinum crispum } \\
\text { (Mill.) Fuss. }\end{array}$ & Perejil & $\begin{array}{l}\text { Hojas comestibles, } \\
\text { condimenticias y } \\
\text { medicinales: diurético, } \\
\text { emenagogo. }\end{array}$ & $\begin{array}{l}\text { MG, IS, } \\
\text { IP, LT }\end{array}$ & Doméstico & $\begin{array}{l}\text { OB, LL, } \\
\text { EA, ES }\end{array}$ & $\begin{array}{l}\text { FB } 529 \\
\text { (LP) }\end{array}$ \\
\hline \multicolumn{7}{|l|}{ Araliaceae } \\
\hline $\begin{array}{l}\text { Tetrapanax papyrifera } \\
\text { (Hook.) K. Koch }\end{array}$ & Ambay & $\begin{array}{l}\text { Hojas medicinales: } \\
\text { para afecciones de } \\
\text { las vías respiratorias, } \\
\text { antiasmático, antitusivo, } \\
\text { expectorante. }\end{array}$ & $\begin{array}{l}\text { MG, IS, } \\
\text { IP }\end{array}$ & Doméstico & $\mathrm{OB}, \mathrm{EA}$ & $\begin{array}{l}\text { FB } 499 \\
\text { (LP) }\end{array}$ \\
\hline \multicolumn{7}{|l|}{ ASPHODELACEAE } \\
\hline Aloe arborescens Mill. & Aloe & $\begin{array}{l}\text { Hojas medicinales: en } \\
\text { uso externo, antiderma- } \\
\text { tósico, vulnerario. }\end{array}$ & IP & Doméstico & $\mathrm{OB}, \mathrm{EA}$ & $\begin{array}{l}\text { FB } 519 \\
(\mathrm{LP})\end{array}$ \\
\hline
\end{tabular}




\begin{tabular}{|c|c|c|c|c|c|c|}
\hline Familias/Especies & N. vulgares & $\begin{array}{c}\text { Partes y productos } \\
\text { derivados y sus usos }\end{array}$ & $\begin{array}{c}\text { Locali- } \\
\text { dades }\end{array}$ & $\begin{array}{l}\text { Fines del } \\
\text { cultivo }\end{array}$ & $\begin{array}{l}\text { Releva- } \\
\text { mientos }\end{array}$ & Muestras \\
\hline Aloe vera (L.) Burm. $f$. & Aloe & $\begin{array}{l}\text { Hojas medicinales: } \\
\text { en uso externo, } \\
\text { antidermatósico, } \\
\text { vulnerario, tónico } \\
\text { capilar; en uso interno, } \\
\text { emoliente. }\end{array}$ & $\begin{array}{l}\text { MG, IS, } \\
\text { IP }\end{array}$ & Doméstico & $\begin{array}{l}\text { OB, LL, } \\
\text { EA }\end{array}$ & $\begin{array}{l}\text { FB } 540 \\
\text { (LEBA) }\end{array}$ \\
\hline \multicolumn{7}{|l|}{ Asteraceae } \\
\hline Artemisia absinthium L. & Ajenjo & $\begin{array}{l}\text { Hojas medicinales: } \\
\text { emenagogo, vermífugo. }\end{array}$ & IS & Doméstico & $\mathrm{OB}, \mathrm{EA}$ & $\begin{array}{l}\text { FB } 523 \\
\text { (LEBA) }\end{array}$ \\
\hline Calendula officinalis $\mathrm{L}$. & Caléndula & $\begin{array}{l}\text { Flores y hojas } \\
\text { comestibles, } \\
\text { ornamental, para atraer } \\
\text { insectos; medicinal: } \\
\text { emoliente. }\end{array}$ & IS & Doméstico & $\begin{array}{l}\text { OB, LL, } \\
\text { EA, ES }\end{array}$ & $\begin{array}{l}\text { FB } 526 \\
\text { (LP) }\end{array}$ \\
\hline Cichorium endivia L. & Escarola & Hojas comestibles. & IS, IP & Doméstico & $\begin{array}{l}\text { OB, LL, } \\
\text { EA, ES }\end{array}$ & $\begin{array}{l}\text { FB } 538 \\
\text { (LEBA) }\end{array}$ \\
\hline Cichorium intybus L. & Achicoria & Hojas comestibles. & $\begin{array}{l}\text { MG, IS, } \\
\text { IP, LT }\end{array}$ & Doméstico & $\begin{array}{l}\text { OB, LL, } \\
\text { EA, ES }\end{array}$ & $\begin{array}{l}\text { FB } 515 \\
\text { (LEBA) }\end{array}$ \\
\hline Lactuca sativa $\mathrm{L}$. & $\begin{array}{l}\text { Lechuga } \\
\text { criolla }\end{array}$ & Hojas comestibles. & $\begin{array}{l}\text { MG, IS, } \\
\text { IP, LT }\end{array}$ & Doméstico & $\begin{array}{l}\text { OB, LL, } \\
\text { EA, ES }\end{array}$ & $\begin{array}{l}\text { FB } 539 \\
\text { (LEBA) }\end{array}$ \\
\hline \multicolumn{7}{|l|}{ BRASSICACEAE } \\
\hline $\begin{array}{l}\text { Brassica oleracea L. var. } \\
\text { capitata } \mathrm{L} \text {. }\end{array}$ & Repollo & $\begin{array}{l}\text { Hojas comestibles. } \\
\text { Chucrut artesanal. }\end{array}$ & $\begin{array}{l}\text { MG, IS, } \\
\text { IP, LT } \\
\text { IP }\end{array}$ & $\begin{array}{l}\text { Doméstico } \\
\text { Comercial }\end{array}$ & $\begin{array}{l}\text { OB, LL, } \\
\text { EA, ES }\end{array}$ & $\begin{array}{l}\text { FB } 552 \\
(\text { LEBA) }\end{array}$ \\
\hline Eruca vesicaria (L.) Cav. & Rúcula & $\begin{array}{l}\text { Hojas comestibles y } \\
\text { condimenticias. }\end{array}$ & $\begin{array}{l}\text { MG, IS, } \\
\text { IP }\end{array}$ & Doméstico & $\begin{array}{l}\text { OB, LL, } \\
\text { EA, ES }\end{array}$ & $\begin{array}{l}\text { FB } 382 \\
\text { (LP) }\end{array}$ \\
\hline $\begin{array}{l}\text { Raphanus sativus L. var. } \\
\text { sativus }\end{array}$ & Rabanito & $\begin{array}{l}\text { Raíces comestibles y } \\
\text { medicinales: diurético, } \\
\text { depurativo, digestivo. }\end{array}$ & MG, IS & Doméstico & $\begin{array}{l}\text { OB, LL, } \\
\text { EA }\end{array}$ & $\begin{array}{l}\text { JH } 2151 \\
(\mathrm{LP})\end{array}$ \\
\hline \multicolumn{7}{|l|}{ Chenopodiaceae } \\
\hline $\begin{array}{l}\text { Beta vulgaris L. var. cicla } \\
\text { L. }\end{array}$ & Acelga & Hojas comestibles. & $\begin{array}{l}\text { MG, IS, } \\
\text { IP, LT }\end{array}$ & Doméstico & $\begin{array}{l}\text { OB, LL, } \\
\text { EA, ES }\end{array}$ & $\begin{array}{l}\text { FB } 381 \\
\text { (LP) }\end{array}$ \\
\hline $\begin{array}{l}\text { Beta vulgaris L. var. } \\
\text { vulgaris }\end{array}$ & Remolacha & Raíces comestibles. & $\begin{array}{l}\text { MG, IS, } \\
\text { IP, LT }\end{array}$ & Doméstico & $\begin{array}{l}\text { OB, LL, } \\
\text { EA, ES }\end{array}$ & $\begin{array}{l}\text { FB 568 } \\
\text { (LEBA) }\end{array}$ \\
\hline Spinacia oleracea L. & Espinaca & $\begin{array}{l}\text { Hojas comestibles y } \\
\text { medicinales: para la } \\
\text { anemia y de problemas } \\
\text { de la vista. }\end{array}$ & IS, LT & Doméstico & $\begin{array}{l}\text { OB, LL, } \\
\text { EA, ES }\end{array}$ & $\begin{array}{l}\text { FB } 542 \\
\text { (LP) }\end{array}$ \\
\hline \multicolumn{7}{|l|}{ Convolvulaceae } \\
\hline $\begin{array}{l}\text { Ipomoea batatas }(\mathrm{L} .) \\
\text { Lam. }\end{array}$ & Batata & $\begin{array}{l}\text { Raíces comestibles (no } \\
\text { se elaboran dulces ni } \\
\text { batatas en almíbar). }\end{array}$ & $\begin{array}{l}\text { MG, IS, } \\
\text { IP, LT }\end{array}$ & Doméstico & $\begin{array}{l}\text { OB, LL, } \\
\text { EA, ES }\end{array}$ & $\begin{array}{l}\text { FB } 567 \\
(\mathrm{LEBA})\end{array}$ \\
\hline \multicolumn{7}{|l|}{ Cucurbitaceae } \\
\hline $\begin{array}{l}\text { Citrullus lanatus (Thunb.) } \\
\text { Matsum. \& Nakai }\end{array}$ & Sandía & $\begin{array}{l}\text { Frutos comestibles } \\
\text { (fruta fresca). }\end{array}$ & $\begin{array}{l}\text { MG, IS, } \\
\text { LT }\end{array}$ & Doméstico & $\begin{array}{l}\text { OB, LL, } \\
\text { ES }\end{array}$ & $\begin{array}{l}\text { FB } 505 \\
\text { (LEBA) }\end{array}$ \\
\hline Cucumis melo L. & Melón & $\begin{array}{l}\text { Frutos comestibles } \\
\text { (fruta fresca). }\end{array}$ & $\begin{array}{l}\text { MG, IS, } \\
\text { LT }\end{array}$ & Doméstico & $\begin{array}{l}\mathrm{OB}, \mathrm{LL} \\
\mathrm{ES}\end{array}$ & $\begin{array}{l}\text { FB } 506 \\
\text { (LEBA) }\end{array}$ \\
\hline Cucumis sativus L. & Pepino & Frutos comestibles. & MG, IS & Doméstico & $\begin{array}{l}\text { OB, LL, } \\
\text { EA, ES }\end{array}$ & $\begin{array}{l}\text { FB } 533 \\
\text { (LEBA) }\end{array}$ \\
\hline \multirow[t]{2}{*}{$\begin{array}{l}\text { Cucurbita maxima } \\
\text { Duchesne subsp. maxima }\end{array}$} & $\begin{array}{l}\text { Zapallo } \\
\text { y zapallo }\end{array}$ & Frutos comestibles. & $\begin{array}{l}\text { MG, IS, } \\
\text { IP }\end{array}$ & Doméstico & $\begin{array}{l}\text { OB, LL, } \\
\text { EA }\end{array}$ & $\begin{array}{l}\text { FB } 512 \\
(\text { LEBA) }\end{array}$ \\
\hline & hongo & Dulce artesanal. & IP & Comercial & & \\
\hline
\end{tabular}




\begin{tabular}{|c|c|c|c|c|c|c|}
\hline Familias/Especies & N. vulgares & $\begin{array}{l}\text { Partes y productos } \\
\text { derivados y sus usos }\end{array}$ & $\begin{array}{c}\text { Locali- } \\
\text { dades }\end{array}$ & $\begin{array}{l}\text { Fines del } \\
\text { cultivo }\end{array}$ & $\begin{array}{l}\text { Releva- } \\
\text { mientos }\end{array}$ & Muestras \\
\hline $\begin{array}{l}\text { Cucurbita maxima var. } \\
\text { zapallito (Carriére) Millan }\end{array}$ & Zapallito & Frutos comestibles. & $\begin{array}{l}\text { MG, IS, } \\
\text { LT }\end{array}$ & Doméstico & $\begin{array}{l}\text { OB, LL, } \\
\text { EA, ES }\end{array}$ & $\begin{array}{l}\text { FB } 537 \\
\text { (LEBA) }\end{array}$ \\
\hline $\begin{array}{l}\text { Cucurbita moschata } \\
\text { (Lam.) Poir. }\end{array}$ & Anco & Frutos comestibles. & $\begin{array}{l}\text { MG, IS, } \\
\text { LT }\end{array}$ & Doméstico & $\begin{array}{l}\text { OB, LL, } \\
\text { EA, ES }\end{array}$ & $\begin{array}{l}\text { JH } 6075 \\
\text { (SI) }\end{array}$ \\
\hline $\begin{array}{l}\text { Lagenaria siceraria } \\
\text { (Molina) Standl. }\end{array}$ & Mate & $\begin{array}{l}\text { Frutos para mates y } \\
\text { adornos artesanales. }\end{array}$ & IS & Comercial & $\begin{array}{l}\mathrm{OB}, \mathrm{LL} \\
\mathrm{EA}\end{array}$ & $\begin{array}{l}\text { FB } 498 \\
\text { (LEBA) }\end{array}$ \\
\hline Sechium edule (Jacq.) Sw. & Papa del aire & $\begin{array}{l}\text { Frutos comestibles y } \\
\text { medicinales: diurético, } \\
\text { hipotensor. }\end{array}$ & IS, IP & Doméstico & $\begin{array}{l}\text { OB, LL, } \\
\text { EA, ES }\end{array}$ & $\begin{array}{l}\text { FB } 297 \\
(L P)\end{array}$ \\
\hline \multicolumn{7}{|l|}{ EbENACEAE } \\
\hline Diospyros kaki Thunb. & Caqui & Frutos comestibles & IS, IP & Doméstico & $\begin{array}{l}\mathrm{OB}, \mathrm{LL}, \\
\mathrm{EA}\end{array}$ & $\begin{array}{l}\text { FB } 269 \\
\text { (LP) }\end{array}$ \\
\hline \multicolumn{7}{|l|}{ JUGLANDACEAE } \\
\hline $\begin{array}{l}\text { Carya illinoinensis } \\
\text { (Wangenh.) K. Koch }\end{array}$ & Pecán & $\begin{array}{l}\text { Semillas comestibles. } \\
\text { Nueces de pecán } \\
\text { agregadas en higos en } \\
\text { almíbar. }\end{array}$ & $\begin{array}{l}\text { IP } \\
\text { IP }\end{array}$ & $\begin{array}{l}\text { Doméstico } \\
\text { Comercial }\end{array}$ & $\begin{array}{l}\text { OB, LL, } \\
\text { EA }\end{array}$ & $\begin{array}{l}\text { FB } 277 \\
\text { (LP) }\end{array}$ \\
\hline \multicolumn{7}{|l|}{ LAMIACEAE } \\
\hline $\begin{array}{l}\text { Lavandula angustifolia } \\
\text { Mill. }\end{array}$ & Lavanda & $\begin{array}{l}\text { Partes aéreas } \\
\text { medicinales: para } \\
\text { dolencias digestivas y } \\
\text { respiratorias; para alejar } \\
\text { las polillas. }\end{array}$ & IS, IP & Doméstico & $\begin{array}{l}\text { OB, LL, } \\
\text { EA, ES }\end{array}$ & $\begin{array}{l}\text { FB } 500 \\
\text { (LP) }\end{array}$ \\
\hline Melissa officinalis L. & $\begin{array}{l}\text { Melisa/ } \\
\text { Toronjil }\end{array}$ & $\begin{array}{l}\text { Partes aéreas } \\
\text { condimenticias } \\
\text { y medicinales: } \\
\text { relajante, digestivo, } \\
\text { antiespasmódico, } \\
\text { carminativo. }\end{array}$ & IS & Doméstico & $\begin{array}{l}\text { OB, LL, } \\
\text { EA, ES }\end{array}$ & $\begin{array}{l}\text { FB } 458 \\
\text { (LP) }\end{array}$ \\
\hline Mentha spicata L. & Menta & $\begin{array}{l}\text { Hojas condimenticias y } \\
\text { medicinales: digestivo. }\end{array}$ & MG, IS & Doméstico & $\begin{array}{l}\text { OB, LL, } \\
\text { EA, ES }\end{array}$ & $\begin{array}{l}\text { FB } 405 \\
\text { (LP) }\end{array}$ \\
\hline Ocimum basilicum $\mathrm{L}$. & Albahaca & $\begin{array}{l}\text { Hojas condimenticias y } \\
\text { medicinales: digestivo, } \\
\text { carminativo. }\end{array}$ & $\begin{array}{l}\text { MG, IS, } \\
\text { IP, LT }\end{array}$ & Doméstico & $\begin{array}{l}\text { OB, LL, } \\
\text { EA, ES }\end{array}$ & $\begin{array}{l}\text { FB } 516 \\
\text { (LP) }\end{array}$ \\
\hline Origanum vulgare L. & Orégano & $\begin{array}{l}\text { Hojas condimenticias y } \\
\text { medicinales: digestivo, } \\
\text { pectoral. }\end{array}$ & $\begin{array}{l}\text { MG, IS, } \\
\text { IP }\end{array}$ & Doméstico & $\begin{array}{l}\text { OB, LL, } \\
\text { EA, ES }\end{array}$ & $\begin{array}{l}\text { FB } 520 \\
\text { (LP) }\end{array}$ \\
\hline Rosmarinus officinalis L. & Romero & $\begin{array}{l}\text { Hojas condimenticias, y } \\
\text { medicinales: digestivo, } \\
\text { antiespasmódico. }\end{array}$ & $\begin{array}{l}\text { MG, IS, } \\
\text { IP, LT }\end{array}$ & Doméstico & $\begin{array}{l}\text { OB, LL, } \\
\text { EA, ES }\end{array}$ & $\begin{array}{l}\text { FB } 525 \\
\text { (LP) }\end{array}$ \\
\hline & & Saborizante de licores. & IS & Comercial & & \\
\hline Salvia officinalis L. & Salvia & $\begin{array}{l}\text { Hojas condimenticias y } \\
\text { medicinales: digestivo, } \\
\text { antiespasmódico. }\end{array}$ & IS & Doméstico & $\begin{array}{l}\text { OB, LL, } \\
\text { EA, ES }\end{array}$ & $\begin{array}{l}\text { FB } 527 \\
\text { (LP) }\end{array}$ \\
\hline Thymus vulgaris L. & Tomillo & $\begin{array}{l}\text { Hojas condimenticias y } \\
\text { medicinales: digestivo, } \\
\text { antiespasmódico. }\end{array}$ & IS & Doméstico & $\begin{array}{l}\text { OB, LL, } \\
\text { EA }\end{array}$ & $\begin{array}{l}\text { FB } 524 \\
\text { (LP) }\end{array}$ \\
\hline \multicolumn{7}{|l|}{ LAURACEAE } \\
\hline Laurus nobilis L. & Laurel & $\begin{array}{l}\text { Hojas condimenticias y } \\
\text { medicinales: estomacal, } \\
\text { carminativo. }\end{array}$ & $\begin{array}{l}\text { MG, IP, } \\
\text { LT }\end{array}$ & Doméstico & $\begin{array}{l}\text { OB, LL, } \\
\text { EA, ES }\end{array}$ & $\begin{array}{l}\text { FB } 123 \\
\text { (LP) }\end{array}$ \\
\hline Persea americana Mill. & Palta & Frutos comestibles. & IS, IP & $\begin{array}{l}\text { Doméstico } \\
\text { y comercial }\end{array}$ & $\begin{array}{l}\text { OB, LL, } \\
\text { EA, ES }\end{array}$ & $\begin{array}{l}\text { FB } 152 \\
\text { (SI) }\end{array}$ \\
\hline
\end{tabular}


J. A. Hurrell \& al., Huertos familiares periurbanos de las costas de Buenos Aires

\begin{tabular}{|c|c|c|c|c|c|c|}
\hline Familias/Especies & N. vulgares & $\begin{array}{l}\text { Partes y productos } \\
\text { derivados y sus usos }\end{array}$ & $\begin{array}{c}\text { Locali- } \\
\text { dades }\end{array}$ & $\begin{array}{l}\text { Fines del } \\
\text { cultivo }\end{array}$ & $\begin{array}{l}\text { Releva- } \\
\text { mientos }\end{array}$ & Muestras \\
\hline \multicolumn{7}{|l|}{ LEgUMinosae } \\
\hline $\begin{array}{l}\text { Lablab purpureus (L.) } \\
\text { Sweet }\end{array}$ & $\begin{array}{l}\text { Poroto } \\
\text { japonés }\end{array}$ & Semillas comestibles. & MG, IS & Doméstico & $\begin{array}{l}\text { OB, LL, } \\
\text { EA }\end{array}$ & $\begin{array}{l}\text { FB } 507 \\
\text { (LEBA) }\end{array}$ \\
\hline Phaseolus lunatus L. & $\begin{array}{l}\text { Poroto de } \\
\text { manteca }\end{array}$ & Semillas comestibles. & $\begin{array}{l}\text { MG, IS, } \\
\text { LT }\end{array}$ & Doméstico & $\begin{array}{l}\text { OB, LL, } \\
\text { EA, ES }\end{array}$ & $\begin{array}{l}\text { FB } 530 \\
\text { (LEBA) }\end{array}$ \\
\hline Phaseolus vulgaris L. & Poroto & Semillas comestibles. & MG & Doméstico & $\begin{array}{l}\text { OB, LL, } \\
\text { EA, ES }\end{array}$ & $\begin{array}{l}\text { FB } 532 \\
\text { (LEBA) }\end{array}$ \\
\hline Pisum sativum L. & Arveja & Semillas comestibles. & $\begin{array}{l}\text { IS, IP, } \\
\text { LT }\end{array}$ & Doméstico & $\begin{array}{l}\text { OB, LL, } \\
\text { EA, ES }\end{array}$ & $\begin{array}{l}\text { FB } 379 \\
\text { (LP) }\end{array}$ \\
\hline Vicia faba $\mathrm{L}$. & Haba & Semillas comestibles. & $\begin{array}{l}\text { IS, IP, } \\
\text { LT }\end{array}$ & Doméstico & $\begin{array}{l}\text { OB, LL, } \\
\text { EA, ES }\end{array}$ & $\begin{array}{l}\text { FB } 380 \\
\text { (LP) }\end{array}$ \\
\hline \multicolumn{7}{|l|}{ LYTHRACEAE } \\
\hline Punica granatum $\mathrm{L}$. & Granado & $\begin{array}{l}\text { Frutos comestibles } \\
\text { (fruta fresca) } \\
\text { y medicinales: } \\
\text { astringente, } \\
\text { antidiarreico. }\end{array}$ & IS, LT & Doméstico & $\begin{array}{l}\text { OB, LL, } \\
\text { EA, ES }\end{array}$ & $\begin{array}{l}\text { FB } 535 \\
\text { (LP) }\end{array}$ \\
\hline \multicolumn{7}{|l|}{ Moraceae } \\
\hline Ficus carica $\mathrm{L}$. & Higuera & $\begin{array}{l}\text { Frutos comestibles } \\
\text { (fruta fresca). } \\
\text { Dulce y en almíbar } \\
\text { (solos y con pecán). }\end{array}$ & $\begin{array}{l}\text { IS, IP, } \\
\text { LT } \\
\text { IP }\end{array}$ & $\begin{array}{l}\text { Doméstico } \\
\text { Comercial }\end{array}$ & $\begin{array}{l}\text { OB, LL, } \\
\text { EA, ES }\end{array}$ & $\begin{array}{l}\text { FB } 366 \\
\text { (LP) }\end{array}$ \\
\hline \multicolumn{7}{|l|}{ Musaceae } \\
\hline Musa $\mathrm{x}$ paradisiaca L. & Bananero & $\begin{array}{l}\text { Frutos comestibles } \\
\text { (fruta fresca). Planta } \\
\text { ornamental. }\end{array}$ & $\begin{array}{l}\text { MG, IS, } \\
\text { IP, LT }\end{array}$ & Doméstico & $\begin{array}{l}\mathrm{OB}, \mathrm{LL} \\
\mathrm{EA}, \mathrm{ES}\end{array}$ & $\begin{array}{l}\text { FB } 565 \\
\text { (LEBA) }\end{array}$ \\
\hline \multicolumn{7}{|l|}{ Myrtaceae } \\
\hline $\begin{array}{l}\text { Eucalyptus cinerea F. } \\
\text { Moell. ex Benth. }\end{array}$ & Eucalipto & $\begin{array}{l}\text { Hojas medicinales: } \\
\text { para combatir catarros } \\
\text { bronquitis, antitusivo, } \\
\text { antiasmático, febrífugo. }\end{array}$ & IS & Doméstico & $\mathrm{OB}, \mathrm{EA}$ & $\begin{array}{l}\text { FB } 531 \\
\text { (LP) }\end{array}$ \\
\hline \multicolumn{7}{|l|}{ Oleaceae } \\
\hline Olea europea L. & Olivo & $\begin{array}{l}\text { Aceitunas frescas } \\
\text { comestibles. } \\
\text { Aceitunas en aceite. }\end{array}$ & $\begin{array}{l}\text { IP } \\
\text { IP }\end{array}$ & $\begin{array}{l}\text { Doméstico } \\
\text { Comercial }\end{array}$ & $\begin{array}{l}\mathrm{OB}, \mathrm{LL} \\
\mathrm{EA}, \mathrm{ES}\end{array}$ & $\begin{array}{l}\text { FB } 518 \\
\text { (LP) }\end{array}$ \\
\hline \multicolumn{7}{|l|}{ Poaceae } \\
\hline $\begin{array}{l}\text { Cymbopogon citratus } \\
\text { (DC.) Stapf }\end{array}$ & Pasto limón & $\begin{array}{l}\text { Macollas } \\
\text { condimenticias. }\end{array}$ & IS & Doméstico & $\begin{array}{l}\text { OB, LL, } \\
\text { EA }\end{array}$ & $\begin{array}{l}\text { FB } 522 \\
\text { (LEBA) }\end{array}$ \\
\hline Zea mays $\mathrm{L}$. & Maíz/Choclo & $\begin{array}{l}\text { Frutos comestibles } \\
\text { (infrutescencias } \\
\text { inmaduras). }\end{array}$ & $\begin{array}{l}\text { MG, IS, } \\
\text { IP, LT }\end{array}$ & Doméstico & $\begin{array}{l}\mathrm{OB}, \mathrm{LL} \\
\mathrm{EA}, \mathrm{ES}\end{array}$ & $\begin{array}{l}\text { FB } 541 \\
\text { (LEBA) }\end{array}$ \\
\hline \multicolumn{7}{|l|}{ ROSACEAE } \\
\hline Cydonia oblonga Mill. & Membrillero & $\begin{array}{l}\text { Frutos comestibles } \\
\text { (fruta fresca) }\end{array}$ & $\begin{array}{l}\text { MG, IS, } \\
\text { IP, LT }\end{array}$ & Doméstico & $\begin{array}{l}\text { OB, LL, } \\
\text { EA }\end{array}$ & $\begin{array}{l}\text { FB } 151 \\
\text { (LP) }\end{array}$ \\
\hline $\begin{array}{l}\text { Eriobotrya japonica } \\
\text { (Thunb.) Lindl. }\end{array}$ & Níspero & $\begin{array}{l}\text { Frutos comestibles } \\
\text { (fruta fresca). }\end{array}$ & $\begin{array}{l}\text { IS, IP, } \\
\text { LT }\end{array}$ & Doméstico & $\begin{array}{l}\text { OB, LL, } \\
\text { EA }\end{array}$ & $\begin{array}{l}\text { FB } 270 \\
\text { (LP) }\end{array}$ \\
\hline $\begin{array}{l}\text { Fragaria } \mathrm{x} \text { ananassa } \\
\text { (Weston) Duchesne }\end{array}$ & Frutilla & $\begin{array}{l}\text { Frutos comestibles } \\
\text { (fruta fresca). } \\
\text { Mermelada artesanal. }\end{array}$ & $\begin{array}{l}\text { IS, IP } \\
\text { IP }\end{array}$ & $\begin{array}{l}\text { Doméstico } \\
\text { Comercial }\end{array}$ & $\begin{array}{l}\mathrm{OB}, \mathrm{LL} \\
\mathrm{EA}, \mathrm{ES}\end{array}$ & $\begin{array}{l}\text { FB } 501 \\
\text { (LEBA) }\end{array}$ \\
\hline Malus pumila Mill. & Manzanao & $\begin{array}{l}\text { Frutos comestibles } \\
\text { (fruta fresca). } \\
\text { Mermelada y compota } \\
\text { artesanales. }\end{array}$ & $\begin{array}{l}\text { IS, IP } \\
\text { IP }\end{array}$ & $\begin{array}{l}\text { Doméstico } \\
\text { Comercial }\end{array}$ & $\begin{array}{l}\text { OB, LL, } \\
\text { EA, ES }\end{array}$ & $\begin{array}{l}\text { FB } 511 \\
\text { (LEBA) }\end{array}$ \\
\hline
\end{tabular}




\begin{tabular}{|c|c|c|c|c|c|c|}
\hline Familias/Especies & N. vulgares & $\begin{array}{l}\text { Partes y productos } \\
\text { derivados y sus usos }\end{array}$ & $\begin{array}{c}\text { Locali- } \\
\text { dades }\end{array}$ & $\begin{array}{l}\text { Fines del } \\
\text { cultivo }\end{array}$ & $\begin{array}{l}\text { Releva- } \\
\text { mientos }\end{array}$ & Muestras \\
\hline $\begin{array}{l}\text { Prunus amygdalus (L.) } \\
\text { Batsch }\end{array}$ & Almendro & $\begin{array}{l}\text { Semillas comestibles } \\
\text { (fruta seca). }\end{array}$ & IP & Doméstico & $\begin{array}{l}\text { OB, LL, } \\
\text { EA }\end{array}$ & $\begin{array}{l}\text { FB } 510 \\
\text { (LEBA) }\end{array}$ \\
\hline Prunus armeniaca $\mathrm{L}$. & Damasco & $\begin{array}{l}\text { Frutos comestibles } \\
\text { (fruta fresca). }\end{array}$ & MG & Doméstico & $\begin{array}{l}\mathrm{OB}, \mathrm{LL} \\
\mathrm{EA}\end{array}$ & $\begin{array}{l}\text { FB } 566 \\
\text { (LEBA) }\end{array}$ \\
\hline Prunus avium (L.) L. & Cerezo & $\begin{array}{l}\text { Frutos comestibles } \\
\text { (fruta fresca). }\end{array}$ & IS & Doméstico & $\begin{array}{l}\mathrm{OB}, \mathrm{LL} \\
\mathrm{EA}\end{array}$ & $\begin{array}{l}\text { FB } 536 \\
\text { (LEBA) }\end{array}$ \\
\hline Prunus cerasus L. & Guindo & $\begin{array}{l}\text { Frutos comestibles } \\
\text { (fruta fresca). } \\
\text { Licor artesanal. }\end{array}$ & $\begin{array}{l}\text { MG, IS } \\
\text { IS }\end{array}$ & $\begin{array}{l}\text { Doméstico } \\
\text { Comercial }\end{array}$ & $\begin{array}{l}\text { OB, LL, } \\
\text { EA, ES }\end{array}$ & $\begin{array}{l}\text { FB } 534 \\
\text { (LEBA) }\end{array}$ \\
\hline Prunus domestica L. & Ciruelo & $\begin{array}{l}\text { Frutos comestibles } \\
\text { (fruta fresca). } \\
\text { Vino (licor) y } \\
\text { mermelada artesanal. }\end{array}$ & $\begin{array}{l}\text { MG, IS, } \\
\text { IP, LT } \\
\text { IP }\end{array}$ & $\begin{array}{l}\text { Doméstico } \\
\text { Comercial }\end{array}$ & $\begin{array}{l}\mathrm{OB}, \mathrm{LL} \\
\mathrm{EA}, \mathrm{ES}\end{array}$ & $\begin{array}{l}\text { FB } 326 \\
\text { (LP) }\end{array}$ \\
\hline $\begin{array}{l}\text { Prunus persica (L.) } \\
\text { Batsch }\end{array}$ & Duraznero & $\begin{array}{l}\text { Frutos comestibles } \\
\text { (fruta fresca) }\end{array}$ & $\mathrm{MG}$ & Doméstico & OB, EA. & $\begin{array}{l}\text { JH } 3968 \\
\text { (LP) }\end{array}$ \\
\hline Pyrus communis L. & Peral & $\begin{array}{l}\text { Frutos comestibles } \\
\text { (fruta fresca). } \\
\text { Mermelada artesanal. }\end{array}$ & $\begin{array}{l}\text { IS, IP } \\
\text { IP }\end{array}$ & $\begin{array}{l}\text { Doméstico } \\
\text { Comercial }\end{array}$ & $\begin{array}{l}\text { OB, LL, } \\
\text { EA, ES }\end{array}$ & $\begin{array}{l}\text { FB } 509 \\
\text { (LEBA) }\end{array}$ \\
\hline \multicolumn{7}{|l|}{ Rutaceae } \\
\hline Citrus japonica Thunb. & Quinoto & $\begin{array}{l}\text { Frutos comestibles } \\
\text { (fruta fresca). } \\
\text { Licor artesanal. }\end{array}$ & $\begin{array}{l}\text { MG, IS, } \\
\text { LT } \\
\text { IS }\end{array}$ & $\begin{array}{l}\text { Doméstico } \\
\text { Comercial }\end{array}$ & $\begin{array}{l}\text { OB, LL, } \\
\text { EA, ES }\end{array}$ & $\begin{array}{l}\text { FB } 502 \\
\text { (LP) }\end{array}$ \\
\hline $\begin{array}{l}\text { Citrus } x \text { aurantium L. } \\
\text { (cvs.) }\end{array}$ & Naranjo & $\begin{array}{l}\text { Frutos comestibles } \\
\text { (fruta fresca). } \\
\text { Vino (licor) y } \\
\text { mermelada artesanal. }\end{array}$ & $\begin{array}{l}\text { MG, IS, } \\
\text { IP, LT } \\
\text { IP }\end{array}$ & $\begin{array}{l}\text { Doméstico } \\
\text { Comercial }\end{array}$ & $\begin{array}{l}\text { OB, LL, } \\
\text { EA, ES }\end{array}$ & $\begin{array}{l}\text { FB } 470 \\
\text { (LP) }\end{array}$ \\
\hline $\begin{array}{l}\text { Citrus } x \text { aurantium L. } \\
\text { (cvs.) }\end{array}$ & Pomelo & $\begin{array}{l}\text { Frutos comestibles } \\
\text { (fruta fresca). } \\
\text { Vino (licor) artesanal. }\end{array}$ & $\begin{array}{l}\text { MG, IS, } \\
\text { IP, LT } \\
\text { IP }\end{array}$ & $\begin{array}{l}\text { Doméstico } \\
\text { Comercial }\end{array}$ & $\begin{array}{l}\mathrm{OB}, \mathrm{LL} \\
\mathrm{EA}, \mathrm{ES}\end{array}$ & $\begin{array}{l}\mathrm{JH} 4035 \\
\text { (LP) }\end{array}$ \\
\hline Citrus x limon (L.) Osbeck & Limonero & $\begin{array}{l}\text { Frutos condimenticios y } \\
\text { saborizantes. } \\
\text { Licor artesanal. }\end{array}$ & $\begin{array}{l}\text { MG, IS, } \\
\text { IP, LT } \\
\text { IP }\end{array}$ & $\begin{array}{l}\text { Doméstico } \\
\text { Comercial }\end{array}$ & $\begin{array}{l}\text { OB, LL, } \\
\text { EA, ES }\end{array}$ & $\begin{array}{l}\text { FB } 521 \\
\text { (LEBA) }\end{array}$ \\
\hline Citrus reticulata Blanco & Mandarino & $\begin{array}{l}\text { Frutos comestibles } \\
\text { (fruta fresca). } \\
\text { Licor artesanal. }\end{array}$ & $\begin{array}{l}\text { MG, IS, } \\
\text { IP, LT } \\
\text { IP }\end{array}$ & $\begin{array}{l}\text { Doméstico } \\
\text { Comercial }\end{array}$ & $\begin{array}{l}\text { OB, LL, } \\
\text { EA, ES }\end{array}$ & $\begin{array}{l}\text { JH } 4049 \\
(\mathrm{LP})\end{array}$ \\
\hline \multicolumn{7}{|l|}{ Solanaceae } \\
\hline Capsicum annuum L. & Ají/Morrón & $\begin{array}{l}\text { Frutos comestibles y } \\
\text { condimenticios. } \\
\text { Morrones en aceite. }\end{array}$ & $\begin{array}{l}\text { MG, IS, } \\
\text { IP, LT } \\
\text { IP }\end{array}$ & $\begin{array}{l}\text { Doméstico } \\
\text { Comercial }\end{array}$ & $\begin{array}{l}\text { OB, LL, } \\
\text { EA, ES }\end{array}$ & $\begin{array}{l}\text { FB } 290 \\
\text { (LP) }\end{array}$ \\
\hline Solanum lycopersicum L. & Tomate & $\begin{array}{l}\text { Frutos comestibles. } \\
\text { Mermelada, puré, salsa. }\end{array}$ & $\begin{array}{l}\text { MG, IS, } \\
\text { IP, LT } \\
\text { IP }\end{array}$ & $\begin{array}{l}\text { Doméstico } \\
\text { Comercial }\end{array}$ & $\begin{array}{l}\text { OB, LL, } \\
\text { EA, ES }\end{array}$ & $\begin{array}{l}\text { FB } 383 \\
\text { (LP) }\end{array}$ \\
\hline Solanum melongena $\mathrm{L}$. & Berenjena & $\begin{array}{l}\text { Frutos comestibles. } \\
\text { Berenjenas en } \\
\text { escabeche. }\end{array}$ & $\begin{array}{l}\text { MG, IS, } \\
\text { IP, LT } \\
\text { IP }\end{array}$ & $\begin{array}{l}\text { Doméstico } \\
\text { Comercial }\end{array}$ & $\begin{array}{l}\mathrm{OB}, \mathrm{LL} \\
\mathrm{EA}, \mathrm{ES}\end{array}$ & $\begin{array}{l}\text { FB } 377 \\
\text { (LP) }\end{array}$ \\
\hline Solanum tuberosum L. & Papa & Tubérculos comestibles. & $\begin{array}{l}\text { MG, IS, } \\
\text { IP, LT }\end{array}$ & Doméstico & $\begin{array}{l}\text { OB, LL, } \\
\text { EA, ES }\end{array}$ & $\begin{array}{l}\text { FB } 517 \\
\text { (LEBA) }\end{array}$ \\
\hline \multicolumn{7}{|l|}{ Verbenaceae } \\
\hline Aloysia citriodora Palau & Cedrón & $\begin{array}{l}\text { Partes aéreas } \\
\text { saborizantes } \\
\text { de infusiones y } \\
\text { medicinales: digestivo, } \\
\text { antiespasmódico. }\end{array}$ & IS & Doméstico & $\begin{array}{l}\mathrm{OB}, \mathrm{LL}, \\
\mathrm{EA}\end{array}$ & $\begin{array}{l}\text { JH } 3828 \\
\text { (LP) }\end{array}$ \\
\hline
\end{tabular}




\begin{tabular}{|c|c|c|c|c|c|c|}
\hline Familias/Especies & N. vulgares & $\begin{array}{l}\text { Partes y productos } \\
\text { derivados y sus usos }\end{array}$ & $\begin{array}{c}\text { Locali- } \\
\text { dades }\end{array}$ & $\begin{array}{l}\text { Fines del } \\
\text { cultivo }\end{array}$ & $\begin{array}{l}\text { Releva- } \\
\text { mientos }\end{array}$ & Muestras \\
\hline Lippia turbinata Griseb. & Poleo & $\begin{array}{l}\text { Partes aéreas } \\
\text { saborizantes } \\
\text { de infusiones y } \\
\text { medicinales: diurético, } \\
\text { digestivo, tónico. }\end{array}$ & IS & Doméstico & $\begin{array}{l}\mathrm{OB}, \mathrm{LL}, \\
\mathrm{EA}\end{array}$ & $\begin{array}{l}\text { FB } 508 \\
\text { (LP) }\end{array}$ \\
\hline \multicolumn{7}{|l|}{ Vitaceae } \\
\hline Vitis labrusca $\mathrm{L}$. & $\begin{array}{l}\text { Vid } \\
\text { americana }\end{array}$ & $\begin{array}{l}\text { Frutos para elaborar } \\
\text { vino (vino de la costa). } \\
\text { Grapa, grapa miel y } \\
\text { mermelada artesanal. }\end{array}$ & $\begin{array}{l}\text { IS, IP, } \\
\text { LT } \\
\text { IP }\end{array}$ & $\begin{array}{l}\text { Comercial } \\
\text { Comercial }\end{array}$ & $\begin{array}{l}\text { OB, LL, } \\
\text { EA, ES }\end{array}$ & $\begin{array}{l}\text { FB } 371 \\
\text { (LP) }\end{array}$ \\
\hline Vitis vinifera $\mathrm{L}$. & Vid europea & $\begin{array}{l}\text { Frutos comestibles } \\
\text { (fruta fresca). }\end{array}$ & IS & Doméstico & $\mathrm{OB}, \mathrm{EA}$ & $\begin{array}{l}\text { FB } 503 \\
\text { (LEBA) }\end{array}$ \\
\hline
\end{tabular}

Referencias: MG, Isla Martín García; IS, Isla Santiago; IP, Isla Paulino; LT, Los Talas; OB, observación; LL, listados libres; EA, entrevistas abiertas; ES, entrevistas semiestructuradas.

Tabla 2. Distribución de las especies relevadas en los distintos huertos familiares (numerados) que se encuentran en las diferentes localidades del área de estudio.

\begin{tabular}{|c|c|c|c|c|c|c|c|c|c|c|c|c|c|c|c|c|}
\hline \multirow[t]{2}{*}{ Familias/Especies/Nombres vulgares } & \multicolumn{5}{|c|}{$\begin{array}{c}\text { Isla } \\
\text { Martín García } \\
\text { (MG) }\end{array}$} & \multicolumn{5}{|c|}{$\begin{array}{c}\text { Ensenada } \\
\text { Isla Santiago } \\
\text { (IS) }\end{array}$} & \multicolumn{3}{|c|}{$\begin{array}{c}\text { Berisso } \\
\text { Isla Paulino } \\
\text { (IP) }\end{array}$} & \multicolumn{3}{|c|}{$\begin{array}{c}\text { Berisso } \\
\text { Los Talas } \\
\text { (LT) }\end{array}$} \\
\hline & 1 & 2 & 3 & 4 & 5 & 1 & 2 & 3 & 4 & 5 & 1 & 2 & 3 & 1 & 2 & 3 \\
\hline \multicolumn{17}{|l|}{ ACtinidiaceae } \\
\hline $\begin{array}{l}\text { Actinidia chinensis var.deliciosa/Kiwi } \\
\text { ALLIACEAE }\end{array}$ & 0 & 0 & 0 & 0 & 0 & 0 & 1 & 0 & 0 & 0 & 0 & 0 & 0 & 0 & 0 & 0 \\
\hline Allium cepa var. cepa/Cebolla & 1 & 1 & 1 & 1 & 1 & 1 & 1 & 1 & 1 & 1 & 1 & 1 & 1 & 1 & 0 & 0 \\
\hline Allium ampeloprasum/Puerro & 0 & 1 & 1 & 1 & 0 & 1 & 1 & 1 & 0 & 0 & 1 & 0 & 0 & 1 & 0 & 0 \\
\hline Allium fistulosum/Cebolla de verdeo & 1 & 1 & 1 & 1 & 1 & 1 & 1 & 0 & 0 & 0 & 0 & 0 & 0 & 1 & 0 & 0 \\
\hline Allium schoenoprasum/Ciboulette & 0 & 0 & 1 & 0 & 0 & 1 & 0 & 0 & 0 & 0 & 0 & 0 & 0 & 1 & 0 & 0 \\
\hline \multicolumn{17}{|l|}{ Anacardiaceae } \\
\hline Mangifera indica/Mango & 0 & 0 & 0 & 0 & 0 & 1 & 0 & 0 & 0 & 0 & 0 & 0 & 0 & 0 & 0 & 0 \\
\hline \multicolumn{17}{|l|}{ Apiaceae } \\
\hline Apium graveolens/Apio & 0 & 1 & 1 & 0 & 1 & 1 & 0 & 0 & 0 & 0 & 1 & 0 & 0 & 1 & 0 & 0 \\
\hline Daucus carota subsp. sativus/Zanahoria & 0 & 1 & 0 & 0 & 0 & 0 & 1 & 0 & 0 & 0 & 1 & 0 & 0 & 1 & 0 & 0 \\
\hline Petroselinum crispum/Perejil & 1 & 0 & 1 & 0 & 0 & 1 & 1 & 1 & 1 & 0 & 0 & 1 & 0 & 1 & 0 & 0 \\
\hline \multicolumn{17}{|l|}{ Araliaceae } \\
\hline Tetrapanax papyrifera/Ambay & 0 & 1 & 0 & 0 & 0 & 0 & 0 & 1 & 0 & 0 & 1 & 0 & 0 & 0 & 0 & 0 \\
\hline \multicolumn{17}{|l|}{ ASPHODELACEAE } \\
\hline Aloe arborescens/Aloe & 0 & 0 & 0 & 0 & 0 & 0 & 0 & 0 & 0 & 0 & 1 & 1 & 0 & 0 & 0 & 0 \\
\hline Aloe vera/Aloe & 0 & 0 & 1 & 0 & 0 & 1 & 1 & 0 & 1 & 0 & 1 & 0 & 0 & 0 & 0 & 0 \\
\hline \multicolumn{17}{|l|}{ Asteraceae } \\
\hline Artemisia absinthium/Ajenjo & 0 & 0 & 0 & 0 & 0 & 1 & 0 & 0 & 0 & 0 & 0 & 0 & 0 & 0 & 0 & 0 \\
\hline Calendula officinalis/Caléndula & 0 & 0 & 0 & 0 & 0 & 1 & 0 & 1 & 0 & 0 & 0 & 0 & 0 & 0 & 0 & 0 \\
\hline Cichorium endivia/Escarola & 0 & 0 & 0 & 0 & 0 & 1 & 0 & 0 & 0 & 0 & 0 & 1 & 0 & 0 & 0 & 0 \\
\hline Cichorium intybus/Achicoria & 0 & 1 & 0 & 1 & 1 & 1 & 1 & 0 & 0 & 0 & 0 & 0 & 1 & 1 & 0 & 0 \\
\hline Lactuca sativa/Lechuga & 1 & 1 & 1 & 0 & 1 & 1 & 1 & 1 & 0 & 0 & 0 & 1 & 1 & 1 & 0 & 0 \\
\hline \multicolumn{17}{|l|}{ BRASSICACEAE } \\
\hline Brassica oleracea var. capitata/Repollo & 0 & 1 & 1 & 0 & 0 & 1 & 1 & 0 & 0 & 0 & 0 & 1 & 0 & 1 & 0 & 0 \\
\hline
\end{tabular}




\begin{tabular}{|c|c|c|c|c|c|c|c|c|c|c|c|c|c|c|c|c|}
\hline \multirow[t]{2}{*}{ Familias/Especies/Nombres vulgares } & \multicolumn{5}{|c|}{$\begin{array}{c}\text { Isla } \\
\text { Martín García } \\
\text { (MG) }\end{array}$} & \multicolumn{5}{|c|}{$\begin{array}{c}\text { Ensenada } \\
\text { Isla Santiago } \\
\text { (IS) }\end{array}$} & \multicolumn{3}{|c|}{$\begin{array}{c}\text { Berisso } \\
\text { Isla Paulino } \\
\text { (IP) }\end{array}$} & \multicolumn{3}{|c|}{$\begin{array}{c}\text { Berisso } \\
\text { Los Talas } \\
\text { (LT) }\end{array}$} \\
\hline & 1 & 2 & 3 & 4 & 5 & 1 & 2 & 3 & 4 & 5 & 1 & 2 & 3 & 1 & 2 & 3 \\
\hline Eruca vesicaria/Rúcula & 0 & 1 & 1 & 0 & 0 & 1 & 1 & 0 & 1 & 0 & 1 & 0 & 0 & 0 & 0 & 0 \\
\hline $\begin{array}{l}\text { Raphanus sativus var. sativus/Rabanito } \\
\text { CHENOPODIACEAE }\end{array}$ & 0 & 0 & 1 & 0 & 0 & 1 & 0 & 1 & 0 & 0 & 0 & 0 & 0 & 0 & 0 & 0 \\
\hline Beta vulgaris var. cicla/Acelga & 0 & 1 & 1 & 0 & 1 & 1 & 1 & 1 & 0 & 1 & 1 & 1 & 1 & 1 & 0 & 0 \\
\hline Beta vulgaris var. vulgaris/Remolacha & 0 & 1 & 1 & 0 & 1 & 1 & 1 & 1 & 0 & 1 & 1 & 0 & 1 & 1 & 0 & 0 \\
\hline Spinacia oleracea/Espinaca & 0 & 0 & 0 & 0 & 0 & 0 & 1 & 1 & 0 & 0 & 0 & 0 & 0 & 1 & 0 & 0 \\
\hline Convolvulaceae & & & & & & & & & & & & & & & & \\
\hline $\begin{array}{l}\text { Ipomoea batatas/Batata } \\
\text { CUCURBITACEAE }\end{array}$ & 0 & 1 & 0 & 0 & 0 & 1 & 1 & 0 & 0 & 0 & 0 & 1 & 0 & 1 & 0 & 0 \\
\hline Citrullus lanatus/Sandía & 0 & 1 & 0 & 0 & 1 & 1 & 1 & 0 & 0 & 0 & 0 & 0 & 0 & 1 & 0 & 0 \\
\hline Cucumis melo/Melón & 0 & 1 & 0 & 0 & 1 & 1 & 1 & 0 & 0 & 0 & 0 & 0 & 0 & 1 & 0 & 0 \\
\hline Cucumis sativus/Pepino & 0 & 1 & 0 & 0 & 1 & 1 & 1 & 0 & 0 & 0 & 0 & 0 & 0 & 0 & 0 & 0 \\
\hline Cucurbita maxima subsp. máxima/Zapallo & 1 & 0 & 0 & 0 & 0 & 1 & 1 & 0 & 0 & 0 & 1 & 1 & 1 & 0 & 0 & 0 \\
\hline Cucurbita maxima var. zapallito/Zapallito & 0 & 1 & 0 & 0 & 0 & 1 & 1 & 0 & 0 & 0 & 0 & 0 & 0 & 1 & 0 & 0 \\
\hline Cucurbita moschata/Anco & 0 & 1 & 1 & 1 & 1 & 1 & 1 & 0 & 0 & 1 & 0 & 0 & 0 & 1 & 0 & 0 \\
\hline Lagenaria siceraria/Mate & 0 & 0 & 0 & 0 & 0 & 1 & 0 & 0 & 0 & 0 & 0 & 0 & 0 & 0 & 0 & 0 \\
\hline $\begin{array}{l}\text { Sechium edule/Papa del aire } \\
\text { EBENACEAE }\end{array}$ & 0 & 0 & 0 & 0 & 0 & 0 & 1 & 0 & 0 & 0 & 0 & 1 & 0 & 0 & 0 & 0 \\
\hline $\begin{array}{l}\text { Diospyros kaki/Caqui } \\
\text { JUGLANDACEAE }\end{array}$ & 0 & 0 & 0 & 0 & 0 & 0 & 0 & 1 & 0 & 0 & 0 & 0 & 1 & 0 & 0 & 0 \\
\hline $\begin{array}{l}\text { Carya illinoinensis/Pecán } \\
\text { LAMIACEAE }\end{array}$ & 0 & 0 & 0 & 0 & 0 & 0 & 0 & 0 & 0 & 0 & 0 & 0 & 1 & 0 & 0 & 0 \\
\hline Lavandula angustifolia/Lavanda & 0 & 0 & 0 & 0 & 0 & 1 & 0 & 0 & 1 & 0 & 0 & 1 & 0 & 0 & 0 & 0 \\
\hline Melissa officinalis/Melisa o toronjil & 0 & 0 & 0 & 0 & 0 & 1 & 1 & 0 & 1 & 0 & 0 & 0 & 0 & 0 & 0 & 0 \\
\hline Mentha spicata/Menta & 0 & 0 & 1 & 0 & 0 & 1 & 1 & 1 & 1 & 0 & 0 & 0 & 0 & 0 & 0 & 0 \\
\hline Ocimum basilicum/Albahaca & 1 & 1 & 1 & 0 & 1 & 1 & 1 & 0 & 1 & 1 & 0 & 1 & 0 & 1 & 0 & 0 \\
\hline Origanum vulgare/Orégano & 0 & 1 & 1 & 1 & 0 & 1 & 0 & 0 & 1 & 0 & 1 & 0 & 0 & 0 & 0 & 0 \\
\hline Rosmarinus officinalis/Romero & 1 & 0 & 1 & 0 & 0 & 1 & 0 & 0 & 1 & 0 & 0 & 1 & 0 & 0 & 1 & 0 \\
\hline Salvia officinalis/Salvia & 0 & 0 & 0 & 0 & 0 & 1 & 1 & 0 & 0 & 0 & 0 & 0 & 0 & 0 & 0 & 0 \\
\hline Thymus vulgaris/Tomillo & 0 & 0 & 0 & 0 & 0 & 1 & 0 & 0 & 0 & 0 & 0 & 0 & 0 & 0 & 0 & 0 \\
\hline LAURACEAE & & & & & & & & & & & & & & & & \\
\hline Laurus nobilis/Laurel & 0 & 0 & 0 & 1 & 0 & 0 & 0 & 0 & 0 & 0 & 0 & 1 & 0 & 0 & 1 & 0 \\
\hline $\begin{array}{l}\text { Persea americana/Palta } \\
\text { LEGUMINOSAE }\end{array}$ & 0 & 0 & 0 & 0 & 0 & 1 & 1 & 0 & 0 & 0 & 0 & 1 & 0 & 0 & 0 & 0 \\
\hline Lablab purpureus/Poroto japonés & 0 & 1 & 0 & 0 & 1 & 1 & 0 & 0 & 0 & 0 & 0 & 0 & 0 & 0 & 0 & 0 \\
\hline Phaseolus lunatus/Poroto de manteca & 0 & 0 & 0 & 1 & 0 & 1 & 1 & 0 & 0 & 0 & 0 & 0 & 0 & 1 & 0 & 0 \\
\hline Phaseolus vulgaris/Poroto & 1 & 1 & 0 & 0 & 0 & 0 & 0 & 0 & 0 & 0 & 0 & 0 & 0 & 0 & 0 & 0 \\
\hline Pisum sativum/Arveja & 0 & 0 & 0 & 0 & 0 & 1 & 1 & 0 & 0 & 0 & 0 & 1 & 0 & 1 & 0 & 0 \\
\hline $\begin{array}{l}\text { Vicia faba/Haba } \\
\text { LYTHRACEAE }\end{array}$ & 0 & 0 & 0 & 0 & 0 & 1 & 1 & 1 & 0 & 0 & 0 & 1 & 0 & 1 & 0 & 0 \\
\hline $\begin{array}{l}\text { Punica granatum/ Granado } \\
\text { MORACEAE }\end{array}$ & 0 & 0 & 0 & 0 & 0 & 1 & 1 & 0 & 0 & 0 & 0 & 0 & 0 & 0 & 0 & 1 \\
\hline $\begin{array}{l}\text { Ficus carica/ Higuera } \\
\text { MuSACEAE }\end{array}$ & 0 & 0 & 0 & 0 & 0 & 1 & 1 & 0 & 1 & 0 & 0 & 1 & 1 & 1 & 0 & 1 \\
\hline $\begin{array}{l}\text { Musa X paradisiacal/ Bananero } \\
\text { MYRTACEAE }\end{array}$ & 0 & 0 & 0 & 0 & 1 & 1 & 1 & 0 & 0 & 0 & 1 & 0 & 0 & 0 & 0 & 1 \\
\hline Eucalyptus cinerea/Eucalipto & 0 & 0 & 0 & 0 & 0 & 1 & 0 & 0 & 0 & 0 & 0 & 0 & 0 & 0 & 0 & 0 \\
\hline
\end{tabular}


J. A. Hurrell \& al., Huertos familiares periurbanos de las costas de Buenos Aires

\begin{tabular}{|c|c|c|c|c|c|c|c|c|c|c|c|c|c|c|c|c|}
\hline \multirow[t]{2}{*}{ Familias/Especies/Nombres vulgares } & \multicolumn{5}{|c|}{$\begin{array}{c}\text { Isla } \\
\text { Martín García } \\
\text { (MG) }\end{array}$} & \multicolumn{5}{|c|}{$\begin{array}{c}\text { Ensenada } \\
\text { Isla Santiago } \\
\text { (IS) }\end{array}$} & \multicolumn{3}{|c|}{$\begin{array}{c}\text { Berisso } \\
\text { Isla Paulino } \\
\text { (IP) }\end{array}$} & \multicolumn{3}{|c|}{$\begin{array}{c}\text { Berisso } \\
\text { Los Talas } \\
\text { (LT) }\end{array}$} \\
\hline & 1 & 2 & 3 & 4 & 5 & 1 & 2 & 3 & 4 & 5 & 1 & 2 & 3 & 1 & 2 & 3 \\
\hline \multicolumn{17}{|l|}{ Oleaceae } \\
\hline Olea europea/Olivo & 0 & 0 & 0 & 0 & 0 & 0 & 0 & 0 & 0 & 0 & 0 & 1 & 0 & 0 & 0 & 0 \\
\hline \multicolumn{17}{|l|}{ Poaceae } \\
\hline Cymbopogon citratus/Pasto limón & 0 & 0 & 0 & 0 & 0 & 1 & 0 & 0 & 0 & 0 & 0 & 0 & 0 & 0 & 0 & 0 \\
\hline Zea mays/Maíz o choclo & 0 & 1 & 1 & 0 & 1 & 1 & 1 & 0 & 1 & 1 & 1 & 1 & 0 & 1 & 0 & 0 \\
\hline \multicolumn{17}{|l|}{ Rosaceae } \\
\hline Cydonia oblonga/ Membrillero & 1 & 0 & 0 & 0 & 0 & 0 & 1 & 0 & 0 & 0 & 0 & 0 & 1 & 0 & 0 & 1 \\
\hline Eriobotrya japonica/Níspero & 0 & 0 & 0 & 0 & 0 & 1 & 1 & 0 & 0 & 0 & 0 & 0 & 1 & 0 & 1 & 1 \\
\hline Fragaria $\mathrm{x}$ ananassa/Frutilla & 0 & 0 & 0 & 0 & 0 & 1 & 1 & 0 & 0 & 0 & 0 & 0 & 1 & 0 & 0 & 0 \\
\hline Malus pumila/ Manzano & 0 & 0 & 0 & 0 & 0 & 1 & 1 & 0 & 0 & 0 & 0 & 0 & 1 & 0 & 0 & 0 \\
\hline Prunus amygdalus/Almendro & 0 & 0 & 0 & 0 & 0 & 0 & 0 & 0 & 0 & 0 & 0 & 0 & 1 & 0 & 0 & 0 \\
\hline Prunus armeniaca/Damasco & 1 & 1 & 0 & 1 & 0 & 0 & 0 & 0 & 0 & 0 & 0 & 0 & 0 & 0 & 0 & 0 \\
\hline Prunus avium/ Cerezo & 0 & 0 & 0 & 0 & 0 & 1 & 0 & 0 & 0 & 0 & 0 & 0 & 0 & 0 & 0 & 0 \\
\hline Prunus cerasus/ Guindo & 1 & 0 & 0 & 0 & 0 & 1 & 0 & 0 & 0 & 0 & 0 & 0 & 0 & 0 & 0 & 0 \\
\hline Prunus domestica/Ciruelo & 1 & 0 & 1 & 0 & 0 & 1 & 1 & 0 & 0 & 0 & 0 & 0 & 1 & 0 & 1 & 1 \\
\hline Prunus persica/ Duraznero & 1 & 0 & 0 & 0 & 0 & 0 & 0 & 0 & 0 & 0 & 0 & 0 & 0 & 0 & 0 & 0 \\
\hline Pyrus communis/ Peral & 0 & 0 & 0 & 0 & 0 & 1 & 0 & 0 & 0 & 0 & 0 & 0 & 1 & 0 & 0 & 0 \\
\hline \multicolumn{17}{|l|}{ RUTACEAE } \\
\hline Citrus japonica/Quinoto & 0 & 0 & 1 & 0 & 0 & 1 & 0 & 0 & 0 & 0 & 0 & 0 & 0 & 0 & 1 & 0 \\
\hline Citrus x aurantium cvs./ Naranjo & 1 & 0 & 0 & 1 & 0 & 1 & 1 & 0 & 0 & 0 & 0 & 0 & 1 & 0 & 1 & 0 \\
\hline Citrus x aurantium cvs./Pomelo & 1 & 0 & 0 & 1 & 0 & 1 & 1 & 0 & 0 & 0 & 0 & 0 & 1 & 0 & 1 & 0 \\
\hline Citrus x limon/Limonero & 1 & 0 & 1 & 1 & 0 & 1 & 1 & 0 & 0 & 0 & 1 & 0 & 1 & 0 & 1 & 0 \\
\hline Citrus reticulata/ Mandarino & 1 & 0 & 0 & 1 & 0 & 1 & 1 & 0 & 0 & 0 & 0 & 0 & 1 & 0 & 1 & 1 \\
\hline \multicolumn{17}{|l|}{ Solanaceae } \\
\hline Capsicum annuum/Ají o morrón & 0 & 1 & 1 & 1 & 1 & 1 & 0 & 0 & 0 & 0 & 0 & 1 & 1 & 1 & 0 & 0 \\
\hline Solanum lycopersicum/Tomate & 1 & 1 & 1 & 1 & 1 & 1 & 1 & 0 & 0 & 0 & 1 & 1 & 1 & 1 & 0 & 0 \\
\hline Solanum melongena/Berenjena & 0 & 1 & 0 & 0 & 0 & 1 & 0 & 0 & 0 & 0 & 0 & 1 & 0 & 1 & 0 & 0 \\
\hline Solanum tuberosum/Papa & 0 & 1 & 0 & 0 & 1 & 0 & 1 & 0 & 0 & 0 & 1 & 0 & 0 & 1 & 0 & 0 \\
\hline \multicolumn{17}{|l|}{ VERBENACEAE } \\
\hline Aloysia citriodora/Cedrón & 0 & 0 & 0 & 0 & 0 & 1 & 0 & 0 & 1 & 0 & 0 & 0 & 0 & 0 & 0 & 0 \\
\hline Lippia turbinata/Poleo & 0 & 0 & 0 & 0 & 0 & 1 & 0 & 0 & 1 & 0 & 0 & 0 & 0 & 0 & 0 & 0 \\
\hline \multicolumn{17}{|l|}{ Vitaceae } \\
\hline Vitis labrusca/Vid americana & 0 & 0 & 0 & 0 & 0 & 1 & 1 & 0 & 1 & 0 & 0 & 1 & 1 & 1 & 1 & 1 \\
\hline Vitis vinifera/ Vid europea & 0 & 0 & 0 & 0 & 0 & 0 & 1 & 0 & 0 & 0 & 0 & 0 & 0 & 0 & 0 & 0 \\
\hline
\end{tabular}

relevados). Los huertos familiares con menor cantidad de taxones corresponden a Los Talas, donde se encuentran los viñedos de mayor desarrollo.

Entre las especies más frecuentes en todos los huertos relevados se hallan Alium cepa L. (14/16 huertos), Beta vulgaris L. var. cicla L. y Solanum lycopersicum L. (11/16 cada una), Beta vulgaris L. var. vulgaris, Lactuca sativa L., Ocimum basilicum L. y Zea mays L. (10/16 cada una). Los taxones menos frecuentes, hallados sólo en uno de los huertos, son:
Actinidia chinensis Planch. var. deliciosa (A. Chev.) A. Chev., Artemisia absinthium L., Carya illinoinensis (Wangenh.) K. Koch, Cymbopogon citratus (DC.) Stapf, Eucalyptus cinerea $\mathrm{F}$. Muell ex Benth., Lagenaria siceraria (Molina) Standl., Mangifera indica L., Olea europea L., Prunus amygdalus (L.) Batsch, $P$. avium (L.) L., P. persica (L.) Batsch, Thymus vulgaris L. y Vitis vinifera L. El cultivo de Actinidia chinensis var. deliciosa en Isla Santiago es relictual en la actualidad; sin embargo, constituyó en el pasado un extenso 
producto comercial, pionero en la región.

La mayoría de las verduras y legumbres son especies de uso generalizado (acelga, ají, berenjena, cebolla, choclo, espinaca, lechuga, papa, repollo, tomate, zapallo). No obstante, se cultiva Sechium edule (Jacq.) Sw. (Isla Santiago, Isla Paulino), especie mesoamericana cuya presencia es significativa, dado que se vincula con tradiciones familiares. Las plantas aromáticas ocupan un lugar frecuente en las huertas: albahaca, melisa, menta, orégano, romero, entre otras. Apium graveolens L. se consume como verdura, pero sus frutos no se utilizan como condimento (Hurrell \& al., 2008, 2009). La mayoría de las especies condimenticias y saborizantes de bebidas son valoradas, asimismo, por sus usos medicinales (Lamiaceae, Verbenaceae). Otras especies se cultivan sólo por su uso medicinal, como el ajenjo, el aloe, el eucalipto y la lavanda.

Tetrapanax papyrifera (Hook.) K. Koch, es un caso particular; se la denomina "ambay", por la similitud de sus hojas con las de Cecropia pachystachya Trécul. Los usos asignados a T. papyrifera son los que corresponden a C. pachystachya en el Noreste argentino, su área de origen (antitusivo, expectorante, antiasmático, broncodilatador). En Martín García, Isla Santiago e Isla Paulino, se cultiva T. papyrifera pensando que es C. pachystachya: su cultivo se vincula con un conocimiento ligado a tradiciones familiares, referidas a los usos de C. pachystachya. No obstante, T. papyrifera también presenta usos medicinales (béquico, diurético, febrífugo, vermífugo), y se cultiva en la región como planta ornamental (Hurrell \& al., 2004, 2011b). Los frutales más comunes son los ciruelos y los cítricos. Vitis labrusca (el cultivar "Isabella"), es el taxón con más ejemplares cultivados, donde se emplazan viñedos para la explotación comercial (Hurrell \& al., 2010).

A partir de algunas especies, sobre todo en la Isla Paulino, y en menor medida en la Isla Santiago (Tabla 1), se elaboran productos artesanales (dulces, conservas, salsas, licores), sin conservantes ni saborizantes, que se venden en forma de venta directa (Turco \& al., 2006), in situ o en zonas urbanas próximas (Buet \& al., 2010).

Los huertos familiares de Martín García son emprendimientos recientes, si se comparan con los de Ensenada-Berisso, y su producción se destina sólo al consumo familiar. Con las hortalizas y frutas cultivadas no se elaboran productos derivados, excepto de forma muy esporádica. La gran mayoría de estos taxones tienen uso generalizado, excepto Lablab purpureus (L.) Sweet, vinculada con tradiciones familiares; fuera de la isla, esta especie sólo fue hallada en un huerto (el más diverso) de la Isla Santiago. Algunos informantes comentan que obtuvieron semillas del programa Pro-Huerta del INTA, encuadrado en del Plan Nacional de Seguridad Alimentaria, cuya finalidad es obtener una alimentación diversificada, mediante la autoproducción de alimentos frescos (INTA, 2011).

\section{Conclusiones}

Los huertos familiares estudiados son relevantes para el ámbito local; aunque su importancia sea exigua en el contexto regional, por ejemplo, si se comparan con las "quintas" de composición florística más variada del Parque Pereyra Iraola, con unas 100 familias dedicadas a la producción hortícola (que abastece a la conurbación), la selección de cultivares, y la elaboración de diversos productos artesanales. Desde el siglo XIX hasta el XXI, las transformaciones operadas en Ensenada-Berisso, desde la expansión hortícola inicial hasta el abandono, parecen definir un cuadro desalentador. No obstante, en los últimos años, los pobladores locales probaron su interés por recuperar la actividad hortícola, que se expresa tanto en el discurso de los informantes como en la formación de cooperativas que rescatan la actividad vitivinícola local. La población de Martín García, en cambio, en su contexto histórico peculiar, no tiene tradición hortícola, pero sí una tendencia reciente al desarrollo de huertos familiares.

La movilidad característica del ámbito periurbano se hace evidente en el estudio de estos huertos. La expansión de terrenos cultivados, con retroceso de las fisonomías vegetales nativas; la retracción del área dedicada a los cultivos, producto del abandono, 
y la consecuente expansión de la vegetación autóctona; y la recuperación posterior de los cultivos, establecen pulsos donde el sistema biocultural se ajusta a las circunstancias. Esto también ha ocurrido en Martín García, aunque en menor escala que en Ensenada-Berisso. En ese marco, este trabajo constituye un aporte, desde el estudio de los huertos familiares, a la comprensión de la movilidad de las transiciones periurbanas.

Por otro lado, los sectores periurbanos son parte, tanto por razones geográficas como históricas, económicas y sociales, del conjunto de la conurbación (que integra además las áreas urbanas y de vegetación espontánea). En ese sentido, este trabajo aporta a la Etnobotánica urbana, dado que permite revelar, dentro del conocimiento botánico propio de las conurbaciones, los componentes ligados a tradiciones de distinto origen (grupos de inmigrantes, preferencias familiares; inclusive, saberes culinarios y prácticas terapéuticas), que permanecen invisibles para el grueso de la población urbana, pero que constituyen los pilares de la actividad hortícola de la región. Este conocimiento botánico urbano ligado a tradiciones, sirve de base para la conservación de germoplasma (por ejemplo, Sechium edule, Lablab purpureus, Vitis labrusca); por ende, enriquece la agrobiodiversidad local, a la vez que fomenta la elaboración de productos en desuso, como el "vino de la costa". Es destacable que la máxima diversidad se observa en huertos de la Isla Santiago, cuyos habitantes no participan, en su mayoría, de ese emprendimiento vitivinícola. Se considera necesario reflexionar sobre las motivaciones personales en estas situaciones de cambio que, en este caso, como se planteó antes, han llevado a la reinserción de los huertos y jerarquización de cultivos relictuales.

En este contexto, es evidente que la presencia y la reproducción de especies y variedades son el resultado de la coexistencia y combinación de saberes, prácticas y objetivos. Así, los saberes tradicionales devienen adaptaciones dinámicas a condiciones específicas: por su propia funcionalidad, los huertos familiares siempre son sistemas dinámicos. La preservación del conocimiento ligado a tradiciones, evidencia el carácter adaptativo de la horticultura periurbana, en el marco mayor del contexto pluricultural de la conurbación donde se halla inmersa.

\section{Agradecimientos}

Los autores agradecen a los directores y personal de los Herbarios LP y SI, a los colaboradores de los trabajos de campo y a todos los informantes. Este trabajo fue realizado con aportes financieros de la Universidad Nacional de La Plata y del Consejo Nacional de Investigaciones Científicas y Técnicas de la República Argentina.

\section{Bibliografía}

AABA. 2010. Atlas Ambiental de Buenos Aires. Disponible: <http://www.atlasdebuenosaires.gov. ar> [Consulta: 29-V-2011].

ALBUQUERQUE, U. P. \& R. F. LUCENA. 2004. Métodos e técnicas na pesquisa etnobotânica. Livro Rápido/NUPEEA, Recife. 190 pp.

ALBUQUERQUE, U. P., L. ANDRADE \& J. CABALLERO. 2005. Structure and floristics of homegardens in Northeastern Brazil. J. Arid Environments 62: 491-506.

ALEXÍADES, M. N. \& J. W. SHELDON. 1996. Selected guidelines for ethnobotanical research: a field manual. The New York Botanical Garden, New York. 306 pp.

ALFONSÍN, J. 2002. Historias de Martín García. Lola, Buenos Aires. 96 pp.

BARSKY, A. 2005. El periurbano productivo: un espacio en constante transformación. Scripta Nova (Barcelona) 9 (194): 36. Disponible: <http://www. ub.es/geocrit/sn/sn-194-36.htm> [Consulta: 5-VI2011].

— 2010. La agricultura de "cercanías" a la ciudad y los ciclos del territorio periurbano. Reflexiones sobre el caso de la Región Metropolitana de Buenos Aires. En A. Svetlitza de Nemirovsky (ed.), Agricultura periurbana en Argentina y globalización. Escenarios, recorridos y problemas, pp. 15-29. FLACSO, Buenos Aires.

— \& L. FERNÁNDEZ. 2004. ¿Qué diferencias hay entre Gran Buenos Aires, conurbano, Área y Región Metropolitana? Geored 23-24 (octubre). Disponible: $<$ http://www.georedweb.com.ar $>$ [Consultado 5-VI2011].

BENENCIA, R. (ed.). 1997. Área hortícola Bonaerense. Cambios en la producción y su incidencia en los sectores sociales. La Colmena, Buenos Aires. 280 pp. 
, G. QUARANTA, \& R. SOUZA CASADINHO. 2009. Cinturón hortícola de la ciudad de Buenos Aires. Ciccus, Buenos Aires. 336 pp.

BLANCKAERT, I., R. SWENNEN, M. PAREDES, R. ROSAS \& R. LIRA SAADE. 2004. Floristic composition, plant uses and management practices in homegardens of San Rafael Coxcatlán, Valley of Tehuacán, Mexico. J. Arid Environments 57: 179-202

BUET COSTANTINO, F., E. A. ULIBARRI \& J. A. HURRELL. 2010. Las huertas familiares en la isla Paulino (Buenos Aires, Argentina). En M. L. Pochettino, A.H. Ladio \& P. M. Arenas (eds.), Tradiciones y Transformaciones en Etnobotánica, pp. 479-484. CYTED-RISAPRET, San Salvador de Jujuy.

BURKART, A. 1957. Ojeada sinóptica sobre la vegetación del Delta del río Paraná. Darwiniana 11: 457-561.

CABRERA, A. L. 1949. Las comunidades vegetales de los alrededores de La Plata (Provincia de Buenos Aires, República Argentina). Lilloa 20: 296-376.

_ \& G. DAWSON. 1944. La selva marginal de Punta Lara, en la ribera argentina del río de la Plata. Revista Mus. La Plata (n. s.) Bot. 5: 267-382.

CODIGNOTTO, J. 1990. Avance del Delta del Paraná y la Isla Martín García. Actas Gongr. Geol. Argent. (San Juan) 1: 272-275.

DALLA SALDA, L. 1981. El basamento de Martín García. Revista Asoc. Geol. Argent. 36: 9-43.

DAS, T. \& A. K. DAS. 2005. Inventorying plant biodiversity in homegardens. A case study in Barak Valley, Assam, North East India. Current Sci. 89 (1): 155-163.

DEL RÍO, J., J. MAIDANA, A. MOLTENI, M. PÉREZ, M. L. POCHETTINO, L. SOUILLA, G. TITO \& E. TURCO. 2007. El rol de las "quintas" familiares del Parque Pereyra Iraola (Buenos Aires, Argentina) en la conservación de la agrobiodiversidad. Kurtziana 33 (1): 217-226.

FEITO, M. C. 2007. Modalidades de intervención social sobre los horticultores bonaerenses: una mirada antropológica. Avá (Posadas) 10: 78-96.

GARCÍA, M. 2010. Inicios, consolidación y diferenciación de la horticultura platense. En A. Svetlitza de Nemirovsky (ed.), Agricultura periurbana en Argentina y globalización. Escenarios, recorridos y problemas, pp. 69-85. FLACSO, Buenos Aires.

GAYTÁN, C., H. VIBRANS, H. NAVARRO \& M. JIMÉNEZ. 2001. Manejo de huertos familiares periurbanos de San Miguel Tlaixpan, Texcoco, México. Bol. Soc. Bot. México 69: 32-62.

GEMINI, M. 2003. ¿Qué es el Gran Buenos Aires? INDEC, Buenos Aires. 12 pp.

GONZÁLEZ, M. A. \& G. B. RAVIZZA. 1987. Sedimentos estuáricos del Pleistoceno tardío y Holoceno en la Isla Martín García. Revista Asoc.
Geol. Argent. 42: 23-243.

HERNÁNDEZ, M. P., S. M. COLARES \& S. M. CIVITELLA. 2009. Plantas utilizadas en medicina popular en un sector del Partido de Berisso, Buenos Aires, Argentina. Bol. Latinoamer. Caribe Plant. Medic. Aromát. 8 (5): 435-444.

HERNÁNDEZ, M. P., S. M. CIVITELLA \& V. G. ROSATO. 2010. Uso medicinal popular de plantas y líquenes de la Isla Paulino, Provincia de Buenos Aires, Argentina. Bol. Latinoamer. Caribe Plant. Medic. Aromát. 9 (4): 258-268.

HUAI, H. \& A. HAMILTON. 2009. Characteristics and functions of traditional homegardens: a review. Front. Biol. China 4 (2): 151-157.

HURRELL, J. A. (ed.). 2008. Flora Rioplatense 3 (1): 1-334. Lola, Buenos Aires.

- D. H. BAZZANO \& G. DELUCCHI. 2004. Biota Rioplatense IX. Arbustos 2, nativos y exóticos. Lola, Buenos Aires. 288 pp.

— E. A. ULIBARRI, G. DELUCCHI \& M. L. POCHETTINO. 2008. Biota Rioplatense XIII. Plantas aromáticas condimenticias. Lola, Buenos Aires. 272 pp.

_.2009. Biota Rioplatense XIV. Hortalizas. Verduras y legumbres. Lola, Buenos Aires. 240 pp.

_ 2010. Biota Rioplatense XV. Frutas frescas, secas y preservadas. Lola, Buenos Aires. 304 pp.

HURRELL, J. A., G. DELUCCHI \& H. A. KELLER. 2011a. Carya illinoinensis (Juglandaceae) adventicia en la Argentina. Bonplandia 20 (1): 47-54.

HURRELL, J.A., E. A. ULIBARRI, P. M. ARENAS \& M. L. POCHETTINO. 2011b. Plantas de herboristería. Plantas medicinales que se comercializan en herboristerías de la Ciudad de Buenos Aires. Lola, Buenos Aires. 242 pp.

IBODA. 2009. Instituto de Botánica Darwinion. Base de datos. Disponible: <http://www2.darwin.edu. ar/Proyectos/FloraArgentina/FA.asp $>$ [Consulta: 2-VI-2011].

INDEC. 2011. Instituto Nacional de Estadística y Censos. Censo 2001. Disponible: <http://www. indec.mecon.ar/webcenso/index.asp $>$ [Consulta: 22-VI-2011]

INTA. 2011. Instituto Nacional de Tecnología Agropecuaria. Pro-Huerta. Disponible: $<$ http:// www.inta.gov.ar/extension/prohuerta/index.asp $>$ [Consulta: 18-VII-2011].

LAMONT, S., W. HARDY ESHBAUGH \& A. GREENBERG. 1999. Species composition, diversity, and use of homegardens among three Amazonian villages. Econ. Bot. 53 (3): 312-326.

LINCK, T. \& C. SCHIAVO (eds.). 2003. Globalización y Territorio. Ed. Nordan-Comunidad, Montevideo. $172 \mathrm{pp}$.

LLAMBÍ, A. 1973. La Isla Martín García. Ministerio de Bienestar Social, Provincia de Buenos Aires, La Plata. 168 pp. 
MAIDANA, J. A., M. PÉREZ, G. TITO \& E. TURCO. 2005. Ecohorticultura en el Parque Pereyra, La Plata-Berazategui (Buenos Aires, Argentina). LEISA, Revista de Agroecología 20 (4): 42-44.

MARASAS, M. \& I. VELARDE. 2000. Rescate del saber tradicional como estrategia de desarrollo: los viñateros de la costa. Bol. ILEIA 16 (2): 23-24.

MARTIN, G. J. 2004. Ethnobotany. A methods manual. Earthscan, London. 268 pp.

MARTÍNEZ, M. R. M. L. POCHETTINO \& P. M. ARENAS. 2003. La horticultura: estrategia de subsistencia en contextos pluriculturales, Valle del Cuñapirú, Misiones, Argentina. Delpinoa 45: 8998.

MICHELLOD, O. E. 2000. La identidad del paisaje urbano a través de la memoria. Berisso, Argentina. Ed. Al Margen, La Plata. 300 pp.

NAZAREA, V. 1998. Cultural Memory and Biodiversity. University of Arizona Press, Tucson. 300 pp.

PÉREZ, M., G. TITO \& E. TURCO. 2008. La producción sin agrotóxicos del Parque Pereyra Iraola: ¿un sistema agroalimentario localizado en el periurbano? En I. Velarde, A. Maggio \& J. Otero (comps.), Sistemas agroalimentarios localizados en Argentina, pp. 102-121. Instituto Nacional de Tecnología Agropecuaria, Buenos Aires.

POCHETTINO, M. L. 2010. Huertos periurbanos como aporte a la diversidad agrícola, Provincia de Buenos Aires, Argentina. En M. L. Pochettino, A. H. Ladio \& P. M. Arenas (eds.), Tradiciones y Transformaciones en Etnobotánica, pp. 186-192. CYTED-RISAPRET, San Salvador de Jujuy.

—, L. SOUILLA \& E. TURCO. 2006. Adaptación a nuevas condiciones sociales y económicas entre los viejos "quinteros" del Parque Pereyra Iraola (Buenos Aires). VIII Congr. Antropol. Social, Simposio, Salta (en CD).

SANUCCI, L. 1972. Berisso, un reflejo de la evolución Argentina. Municipalidad de Berisso, Berisso. 300 pp.

TROPICOS. 2011. Tropicos.org. Missouri Botanical Garden. Disponible: <http://www.tropicos.org> [Consulta: 15-VI-2011].

TURCO, E., L. SOUILLA \& M. L. POCHETTINO. 2006. Relación entre saberes y prácticas culinarios con la conservación de la agrobiodiversidad. Estudio etnobotánico en el Parque Pereyra Iraola (Buenos Aires, Argentina). VII Congreso Latinoamericano de Sociología Rural. 20-24 de noviembre, Quito (en CD).

VELARDE, I., C. VOGET, G. AVILA, C. LOVISO, E. OROSCO, C. SEPÚLVEDA \& S. ARTAZA. 2008. Influencia de la calidad en el consumo de productos patrimoniales: el caso del sistema agroalimentario del vino de la costa de Berisso. En I. Velarde, A. Maggio \& J. Otero (eds.), Sistemas agroalimentarios localizados en Argentina, pp. 3166. Instituto Nacional de Tecnología Agropecuaria, Buenos Aires.

VOGL, C. R., B. VOGL-LUKASSER \& J. CABALLERO. 2002. Homegardens of Maya migrants in the Palenque District (Chiapas/Mexico). Implications for sustainable rural development. En J. R. Stepp, F. S. Wyndham \& R. K. Zarger (eds.), Ethnobiology and Biocultural Diversity, pp. 631647. University of Georgia Press, Athens.

VOGL, C. R., B. VOGL-LUKASSER \& R. PURI. 2004. Tools and Methods for data collection in ethnobotanical studies of homegardens. Field Methodes 16 (3): 285-306.

VOGL-LUKASSER, B. \& C. R. VOGL. 2004. Ethnobotanical research in homegardens of small farmers in the Alpine region of Osttirol (Austria). An example for bridges built and building bridges. Ethnobot. Res. \& Appl. 2:111-137.

VOGL-LUKASSER, B., C. R. VOGL \& H. BOLHÀRNORDENKAMPF. 2002. Homegarden composition on small peasant farms in the Alpine regions of Eastern Tyrol (Austria) and their role in sustainable rural development. En J. R. Stepp, F. S. Wyndham \& R. K. Zarger (eds.), Ethnobiology and Biocultural Diversity, pp. 648-658. University of Georgia Press, Athens.

WAGNER, G. 2002. Why plants have meanings. En J. R. Stepp, F. S. Wyndham \& R.K. Zarger (eds.), Ethnobiology and Biocultural Diversity, pp. 659667. University of Georgia Press, Athens.

WATSON, J. W. \& P. B. EYZAGUIRRE (eds.). 2002. Home gardens and in situ conservation of plant genetic resources in farming systems. International Plant Genetic Resources Institute, Rome. 184 pp.

Original recibido el 22 de julio de 2011; aceptado el 30 de noviembre de 2011. 
